\title{
$1 \quad$ Single mutation makes Escherichia coli an insect mutualist
}

$3{\text { Ryuichi } \operatorname{Koga}^{1 *} \text {, Minoru Moriyama }}^{1}$, Naoko Onodera-Tanifuji ${ }^{1}$, Yoshiko Ishii $^{1}$, Hiroki Takai ${ }^{1}$,

4 Masaki Mizutani $^{1}$, Kohei Oguchi ${ }^{1}$, Reiko Okura ${ }^{2}$, Shingo Suzuki ${ }^{3}$, Yasuhiro Goto ${ }^{4}$, Tetsuya

5 Hayashi $^{4}$, Masahide Seki ${ }^{5}$, Yutaka Suzuki ${ }^{5}$, Yudai Nishide ${ }^{1,6}$, Takahiro Hosokawa ${ }^{7}$, Yuichi

6 Wakamoto $^{2,8}$, Chikara Furusawa ${ }^{3,8}$, Takema Fukatsu ${ }^{1,9,10 *}$

$8{ }^{1}$ Bioproduction Research Institute, National Institute of Advanced Industrial Science and

9 Technology (AIST), Tsukuba, Japan.

10 2Department of Basic Science, Graduate School of Arts and Sciences, The University of Tokyo, 11 Tokyo, Japan.

$12{ }^{3}$ Center for Biosystem Dynamics Research, RIKEN, Osaka, Japan.

$13{ }^{4}$ Department of Bacteriology, Faculty of Medical Sciences, Kyushu University, Fukuoka, Japan.

$14{ }^{5}$ Laboratory of Systems Genomics, Department of Computational Biology and Medical 15 Sciences, Graduate School of Frontier Sciences, The University of Tokyo, Chiba, Japan.

$16{ }^{6}$ National Agriculture and Food Research Organization (NARO), Institute of Agrobiological 17 Sciences, Tsukuba, Japan.

$18{ }^{7}$ Department of Biology, Faculty of Science, Kyushu University, Fukuoka, Japan.

$19{ }^{8}$ Universal Biology Institute, The University of Tokyo, Tokyo, Japan.

$20{ }^{9}$ Department of Biological Sciences, The University of Tokyo, Tokyo, Japan.

$21{ }^{10}$ Graduate School of Life and Environmental Sciences, University of Tsukuba, Tsukuba, Japan. 


\section{Abstract}

27 We report an experimental system in which Escherichia coli evolves into an insect mutualist.

28 When the essential gut symbiont of the stinkbug Plautia stali was replaced by E. coli, a few

29 survivor insects exhibited specific localization and vertical transmission of $E$. coli. Through

30 trans-generational maintenance with $P$. stali, several hyper-mutating E. coli lines independently

31 evolved host's high adult emergence and improved body color. Such "mutualistic" E. coli lines

32 exhibited independent mutations disrupting the carbon catabolite repression (CCR) global

33 transcriptional regulator. Each of the mutations reproduced the mutualistic phenotypes when

34 introduced into wild-type $E$. coli, confirming that the single CCR mutations instantly make $E$.

35 coli an insect mutualist. Our discovery uncovers that evolution of elaborate mutualism can

36 proceed more easily and rapidly than conventionally envisaged. 
Microbial symbioses are among the major evolutionary drivers underpinning the biodiversity $(1,2)$. How ordinary free-living microbes have become sophisticated mutualists is an important but unanswered question in understanding the evolution of symbiosis. To address this fundamental issue, experimental evolutionary approaches may provide valuable insights (3-8). Here we report a novel experimental system in which the model bacterium Escherichia coli evolves into an insect mutualist, thereby demonstrating that evolution of mutualism can proceed very easily and quickly via disruption of a global transcriptional regulator system.

\section{$E$. coli potentially capable of symbiosis with $P$. stali}

Plant-sucking heteropteran bugs generally possess specific symbiotic bacteria in the midgut, which contribute to their growth and survival via provisioning of essential amino acids and/or vitamins $(9,10)$. The brown-winged green stinkbug Plautia stali (Hemiptera: Pentatomidae) (Fig. 1a) develops a specialized symbiotic organ consisting of numerous crypts in a posterior region of the midgut (Fig. 1b). The crypt cavities are densely populated by a specific bacterial symbiont of the genus Pantoea (Fig. 1c, d). The symbiont is essential for growth and survival of the host insect. Normal insects infected with the uncultivable obligatory symbiont, Pantoea sp. A $(11,12)$, attained over $70 \%$ adult emergence rates (Fig. 1e), smeared the symbiont cells onto the eggs upon oviposition (Fig. 1f), and transmitted the symbiont vertically to the offspring via nymphal probing of the eggshell (Fig. 1g). Aposymbiotic insects generated by egg surface sterilization died out with no adult emergence (Fig. 1e). Non-symbiotic bacteria, such as Bacillus subtilis and Burkholderia insecticola, cannot establish infection and symbiosis with $P$. stali (11). Meanwhile, when E. coli was inoculated to sterilized newborn nymphs, the insects certainly exhibited retarded growth and high mortality, but a small number of adult insects emerged, attaining 5-10\% adult emergence rates (Fig. 1e; fig. S1) (11). Such adult insects, which were dwarf in size and dark in color (Fig. 1h), tended to die early, but some insects managed to survive, mate, and produce a small number of eggs. We dissected and inspected these insects, and found that, surprisingly, although the symbiotic organ was atrophied (Fig. 1i), E. coli localized to the midgut crypts just like the original symbiont, although the infection patterns were often patchy (Fig. 1j, k; fig. S2). Furthermore, E. coli cells were smeared on the eggshell and vertically transmitted to the offspring (Fig. 11, m), although the transmission rates and the infection titers were unstable in comparison with those of the original symbiont (Fig. 11). These results suggested that, though incipiently, E. coli is capable of localized infection, vertical transmission, and supporting host survival in P. stali. Considering that $E$. coli belongs to the same Enterobacteriaceae as the original Pantoea symbiont, E. coli may be able to co-opt

73 the mechanisms for infection and localization of the symbiont to establish the incipient 
symbiosis (11). In this context, it seems relevant that, in the stinkbug family Pentatomidae, the gut symbiotic bacteria have evolved repeatedly from the Enterobacteriaceae through recurrent acquisitions and replacements $(13,14)$.

\section{Experimental evolution using hyper-mutating $E$. coli}

This finding prompted us to apply experimental evolutionary approaches to the P. stali-E. coli relationship. By continuously inoculated to and maintained with $P$. stali, would E. coli improve the symbiosis-related traits and finally evolve into a symbiont-like entity? Considering the expected difficulty in observing the evolution of elaborate symbiosis in a realistic time frame, we adopted the hyper-mutating $E$. coli strain, $\Delta$ mutS, in which the DNA mismatch repair enzyme gene mutS is disrupted and the molecular evolutionary rate is elevated by two orders of magnitude (15). The E. coli strain of the same genetic background, $\Delta \mathrm{intS}$, in which the phage integrase gene is disrupted, was used as control. Two selection schemes, growth selection and color selection, were conducted (fig. S3). In growth selection lines (GmL for hyper-mutating $\Delta$ mutS lines; GiL for non-mutating $\Delta$ intS lines), the first-emerged adult insect was subjected to dissection of the symbiotic organ for inoculation to the next generation as well as freeze storing. In color selection lines (CmL for $\Delta$ mutS lines; $\mathrm{CiL}$ for $\Delta \mathrm{intS}$ lines), the most greenish adult insect was subjected to dissection of the symbiotic organ for inoculation to the next generation as well as freeze storing. Throughout the evolutionary experiments, the host insects were supplied from a mass-reared inbred population of $P$. stali, thereby homogenizing the host genetic background and focusing on the evolutionary changes of the E. coli side. Since it takes around 1 month for newborn nymphs of $P$. stali to become adults under the rearing condition, it was expected that, ideally, we would be able to run 12 host generations per year. Actually, however, it took almost for two years because (i) the E. coli-inoculated insects generally exhibited high mortality and retarded growth, (ii) for keeping the insects under a good condition, frequent care without overcrowding was essential, which limited the manageable number of insects per evolutionary line ranging from 50 to 100, and (iii) consequently, extended generation time and stochastic extinction of the evolutionary lines frequently occurred, which had to be restarted from the frozen $E$. coli stocks.

\section{Evolution of mutualistic $E$. coli}

105 We established and maintained $12 \mathrm{CmL}$ color selection lines with $11 \mathrm{CiL}$ control lines, and 7

106 GmL growth selection lines with 7 CiL control lines (Fig. 2a, b). While the control DintS107 infected lines almost constantly exhibited low adult emergence rates, some of the hyper108 mutating $\Delta$ mutS-infected lines started to produce more adult insects. Notably, in a color 
selection line CmL05, the adult emergence rate jumped up at generation 7, and the high emergence rates were maintained thereafter (Fig. 2a). In a growth selection line GmL07, the

111 adult emergence rate improved as early as at generation 2, which was maintained thereafter

112 (Fig. 2b). In CmL05 and GmL07, coincident with the improvement of the adult emergence rate, 113 body color of the adult insects improved from dark to greenish (Fig. 2a-c; fig. S4), and 114 furthermore, the colony morphology of $E$. coli changed from large and flat with rich 115 extracellular matrix to small and convex with little extracellular matrix (Fig. 2c). When the 116 frozen stocks of $\mathrm{CmL} 05$ and GmL07 were inoculated to P. stali, the improved adult emergence 117 rate, the greenish body color, and the small and convex colony shape were reproducibly 118 observed (Fig. 2d, e; fig. S5). These results indicated that some evolutionary lines of hyper119 mutating E. coli have developed mutualistic traits for the host insect and that the phenotypic effects are attributable to genetic changes in the evolutionary E. coli lines.

\section{Microbial traits of mutualistic $E$. coli}

123 In addition to the colony size, shape and extracellular matrix on agar plates (Fig. 2c), the 124 mutualistic E. coli lines CmL05 and GmL07 in culture exhibited distinct microbial traits in 125 comparison with the original E. coli strains: slower growth rate, smaller cell size, loss of 126 flagellar motility, and unstable cell shape (fig. S6a-g). Within the host insect, the evolutionary E. coli lines CmL05 and GmL07 showed significantly higher infection densities than the original E. coli strains (fig. S6h). These observations revealed that the mutualistic E. coli lines certainly have developed a variety of "symbiont-like" microbial traits.

\section{Transcriptomics and genomics of mutualistic $E$. coli}

132 An aliquot of the dissected symbiotic organ from each generation of the color selection line

133 CmL05 was subjected to RNA sequencing, from which E. coli-derived reads were extracted 134 and analyzed (tables S1 and S2). Interestingly, the gene expression patterns of E. coli at 135 generations 7-14 after the improvement of host phenotypes were separately clustered in contrast 136 to those at generations 1-6 before the improvement (Fig. 3a). In the growth selection line 137 GmL07, similarly, the gene expression patterns of E. coli at generations 2-12 after the 138 improvement were distinct from that at generation 1 before the improvement and also from 139 those of the other growth selection lines GmL02 and GmL04 in which the improvement of host 140 phenotypes did not occur (Fig. 3b; tables S1 and S3). These results suggested that the evolution 141 of the mutualistic E. coli lines entails specific and global change of gene expression patterns.

142 In the growth selection line GmL07 and the color selection line CmL05, we surveyed 143 differentially expressed genes before and after the improvement of host phenotypes (table S4), 
144 which identified 193 commonly down-regulated genes and 95 commonly up-regulated genes across GmL07 and CmL05 (fig. S7a, b). The commonly down-regulated genes contained a number of metabolism-related genes such as transporter genes for sugars and other nutrients like maltose, ribose, galactitol, trehalose, mannose, branched chain amino acids, etc., 148 glyoxylate bypass genes, fatty acid degradation genes, and others. Notably, core genes involved in extracellular matrix (= Curli fimbriae) production were significantly down-regulated after the improvement (fig. S7c), which accounted for the altered colony morphology of E. coli associated with the improvement of host phenotypes (see Fig. 2c).

The improved lines CmL05 and GmL07 and the non-improved lines GmL02 and GmL04 were subjected to genome sequencing throughout the evolutionary course (table S5), which identified many mutations accumulated in the hyper-mutating E. coli lines (tables S6 and S7; fig. S8). In an attempt to identify candidate mutations that are correlated with the improvement of the host phenotypes, we surveyed the mutations that appeared at generation 7 of CmL05 and then fixed, which yielded 7 candidate genes, and also the mutations that appeared at generation 2 of GmL07 and then fixed, which yielded 9 candidate genes (Fig. 3c).

\section{Disrupted CCR pathway in mutualistic E. coli}

161 Of these candidates, we focused on a frame shift mutation that disrupted adenylate cyclase 162 (CyaA) in CmL05, and a non-synonymous mutation that changed a functionally important 163 cAMP binding site of cAMP receptor protein (Crp) from leucine to proline in GmL07 (Fig. 3d). 164 Despite their independent origins in distinct evolutionary lines, CyaA and Crp are pivotal components of the same global metabolic regulator system, the carbon catabolite repression (CCR) pathway, operating in diverse bacteria including E. coli $(16,17)$ (Fig. 3e). With sufficient availability of glucose as the primary carbon source for E. coli, the CCR components are subjected to glucose-mediated suppression, being in an unphosphorylated form incapable of activating CyaA, by which the intracellular cAMP is maintained at a low level (fig. S9a). When glucose is used up, the glucose-mediated suppression is released, by which the CCR components are phosphorylated and activate CyaA, which results in an elevated intracellular cAMP level and promotes cAMP binding to Crp. The resultant global transcriptional regulator

173 Crp-cAMP activates and/or represses several hundreds of operons throughout the bacterial 174 genome, referred to as the Crp-cAMP regulon, by which the bacterial metabolic pathways are 175 switched to exploit other carbon sources for adaptation to nutrient-deficient and/or high 176 bacterial density conditions (fig. S9b) $(18,19)$. According to RegulonDB (20), the Crp-cAMP 177 regulon of $E$. coli consists of some 390 up-regulated genes and 80 down-regulated genes (fig. 178 S9c), which are involved in, for example, up-regulation of transporters and catabolic enzymes 
179 for non-glucose sugars (21), quorum sensing induction (22), and production of extracellular 180 matrix (23).

181 Both the CyaA mutation in CmL05 and the Crp mutation in GmL07 are disruptive of the 182 CCR pathway. Considering that $E$. coli cells are packed in the host symbiotic organ very densely 183 (see Fig. 1k; fig. S2i, k), it seems likely that the symbiotic E. coli may be under a nutrient184 limited condition within the host insect, at least locally. If so, it is expected that, in the 185 evolutionary E. coli lines, while the Crp-cAMP transcriptional regulator was activated before 186 the mutations occurred, the activation was disabled after the mutations occurred. Notably, of 187193 genes commonly down-regulated after the CyaA mutation in CmL05 and the Crp mutation 188 in GmL07, 55 genes were reported as activated by Crp-cAMP (fig. S10a). These genes, which 189 are expected to be silenced upon disruption of the CCR system, were significantly down190 regulated in CmL05 and GmL07, which represented many transporter genes for non-glucose 191 sugars, carbohydrate metabolism genes, quorum sensing genes, extracellular matrix production genes, transcription factor genes, and others (fig. S10b-i).

\section{Disrupted CCR genes make $E$. coli an insect mutualist}

195 In order to test whether these mutations are involved in the mutualistic traits of the evolutionary E. coli lines, we prepared E.coli strains that carry the mutations under the wild-type genetic background: the strain $\Delta$ cyaA in which cyaA gene is disrupted; and the strain $\operatorname{crp}^{221 \mathrm{~T}>\mathrm{C}}$ whose crp gene was engineered to carry the leucine-proline replacement at the cAMP binding site. Both the mutant E. coli strains exhibited small and convex colonies with little extracellular matrix, somewhat slower growth rate, smaller cell size, and loss of flagellar motility (Fig. 4a; fig. S11a-e), which were generally reminiscent of the characteristic traits of the improved evolutionary E. coli lines CmL05 and GmL07 (Fig. 2c; fig. S6a-e). When the mutant E. coli strains were inoculated to sterilized newborn nymphs of $P$. stali, both the $\Delta$ cyaA-infected insects and the $\operatorname{crp}^{221 \mathrm{~T}>\mathrm{C}}$-infected insects exhibited remarkably high adult emergence rates, which were comparable to the insects infected with the improved evolutionary E. coli lines and were significantly higher than the insects infected with the control E. coli strains (Fig. 4b). Moreover, the $\Delta$ cyaA-infected insects and the $\operatorname{crp}^{221 \mathrm{~T}>\mathrm{C}}$-infected insects were greenish in color, which were comparable to the greenish insects infected with the improved evolutionary E. coli lines and distinct from the dwarf brown insects infected with the control E. coli strains (Fig. $4 \mathrm{c})$. On the other hand, infection densities of $\operatorname{crp}^{221 \mathrm{~T}>\mathrm{C}}$ and $\Delta$ cyaA were not comparable to those of the improved evolutionary E. coli lines (fig. S11f). These results demonstrated that, strikingly,

212 the single mutations that disrupt the CCR global regulator system make $E$. coli mutualistic to 213 the host insect $P$. stali. 


\section{Discussion}

216 We established an experimental insect- $E$. coli symbiotic system in which the model bacterium

217 is localized to host symbiotic organ, transmissible to host offspring vertically, and supportive

218 of host survival, though incompletely. By infecting and passaging a hyper-mutating E. coli

219 strain with the host insect trans-generationally, several evolutionary lines rapidly developed

220 improved adult emergence and body color, realizing recurrent evolution of mutualism in the

221 laboratory. Strikingly, the E. coli's evolution into the insect mutualist was ascribed to single

222 mutations that convergently disrupted the bacterial CCR pathway, uncovering unexpected

223 involvement of the nutrient-responsive global transcriptional regulator in the establishment of 224 symbiosis.

225 Our finding sheds new light on the evolvability of symbiosis - elaborate mutualistic 226 symbiosis can evolve much more easily and rapidly than conventionally envisaged. We suggest 227 the possibility that the inactivation of the CCR global regulator may represent a pivotal 228 evolutionary step at an early stage of symbiosis. Densely packed in the symbiotic organ, the symbiotic bacteria are expected to constantly suffer nutritional shortage and activate the CCR pathway in vain, which may incur substantial metabolic cost and destabilize the symbiotic association. In this context, the disruption of the CCR pathway should benefit and stabilize the symbiosis. Our finding may be also relevant to the general evolutionary trend of symbiont genomes toward size reduction (24) and lack of transcription factors (25). The disruption of the CCR pathway causes silencing of otherwise activated about 400 genes under the Crp-cAMP regulon (20), which accounts for about $10 \%$ of the whole $E$. coli genome and provides potential targets for gene disruption, IS bombardment, intragenomic recombination, and reductive genome evolution. We propose that, although speculative, inactivation of transcriptional regulators and genome size reduction might have concurrently proceeded in this way during the symbiont genome evolution.

240 The P. stali-E. coli experimental symbiotic system will open a new window to directly 241 observe and analyze the evolutionary processes and mechanisms of mutualistic symbiosis in real-time. E. coli is among the best understood cellular organisms, whose 4.5-5.5 Mb genome encodes over 4,000 genes and around $70 \%$ of them are with functional information $(26,27)$.

244 Laboratory evolution of mutualism using such a model bacterium with ample technological and genetic resources will lead to an ultimate understanding of the symbiotic evolution. Considering that $E$. coli represents a universal component of the gut microbiome of human, mouse, and other vertebrates (28), the insect-E. coli system in combination with the germfree mouse- $E$. coli experimental evolution systems $(29,30)$ would enable us to pursue not only the differences but 
249 also the commonality underpinning the mechanisms of gut symbiosis across vertebrates and

250 invertebrates.

\section{Methods}

253 Insect and bacterial strains used in this study

254 An inbred laboratory strain of the brown-winged green stinkbug $P$. stali was established from several adult insects collected at Tsukuba, Ibaraki, Japan in September 2012, and has been maintained in the laboratory for years. This strain is associated with an essential and uncultivable gut symbiont Pantoea sp. A (11) in a posterior midgut region specialized as the symbiotic organ (Fig. 1; fig. S2). The insects were reared on raw peanuts, soybeans and water containing $0.05 \%$ ascorbic acid (Merck, Germany) at $25 \pm 1{ }^{\circ} \mathrm{C}$ and $50 \pm 5 \%$ relative humidity

260 under a long-day regime of $16 \mathrm{~h}$ light and $8 \mathrm{~h}$ dark.

261 E. coli strains and mutants used in this study are listed below. The mutants $\Delta$ intS, $\Delta$ mutS and $262 \operatorname{crp}^{221 \mathrm{~T}>\mathrm{C}}$ were generated as described later.

\begin{tabular}{|l|l|l|}
\hline Name & Description & Reference \\
\hline BW25113 & Obtained from National Bio Resource Project (NBRP) & 31 \\
\hline$\Delta$ intS & The intS gene was replaced with kanamycin resistance gene. & This study \\
\hline$\Delta$ mutS & The mutS gene was removed from $\Delta$ intS. & This study \\
\hline$\Delta$ cyaA & $\begin{array}{l}\text { Obtained from Keio single-gene knock-out mutant library } \\
\text { via NBRP }\end{array}$ & 27 \\
\hline Crp ${ }^{221 T>C}$ & $\begin{array}{l}\text { A nonsynonymous single nucleotide substitution was } \\
\text { introduced in the crp gene }\end{array}$ & This study \\
\hline CmL05G13a & $\begin{array}{l}\text { An E. coli clone isolated from the glycerol stock of } \\
\text { CmL05G13. }\end{array}$ & This study \\
\hline GmL07G12a & $\begin{array}{l}\text { An E. coli clone isolated from the glycerol stock of } \\
\text { GmL07G12. }\end{array}$ & This study \\
\hline EPI300 & Obtained from Epicentre & N.A. \\
\hline DH5 $\alpha$ & Common laboratory strain & N.A. \\
\hline JM109 & Common laboratory strain & N.A. \\
\hline BL21 & Common laboratory strain & \\
\hline & & \\
\hline
\end{tabular}

\section{Construction of E. coli mutants}

265 The E. coli mutant $\Delta$ intS was established by replacing intS gene of $E$. coli BW25113 with nptII

266 gene that confers kanamycin resistance by $\lambda$-Red homologous recombination using the $267 \mathrm{pRed} / \mathrm{ET}$ plasmid (Gene Bridges, Germany). The E. coli mutant $\Delta$ mutS was established by 268 replacing mutS gene of $\Delta$ intS with the FRT-Cm-FRT cassette (Gene Bridges, Germany) by $\lambda$ 269 Red homologous recombination, and then $\mathrm{Cm}^{\mathrm{R}}$ was eliminated by Flp-FRT recombination. The 270 E. coli mutant $\mathrm{crp}^{221 \mathrm{~T}>\mathrm{C}}$ was established from $\Delta$ intS by replacing the $221^{\text {st }}$ nucleotide $\mathrm{T}$ of the 271 wild type crp gene with $\mathrm{C}$, which changed $74^{\text {th }}$ amino acid leucine of the Crp protein to proline. 
272 This replacement was introduced by MAGE method (32) with a 90-mer DNA oligo (5'-

273 taaagaaatg-atcctctcct-atctgaatca-gggtgatttt-attggcgaac-Cogggctgtt-tgaagagggc-caggaacgta-

274 gcgcatgggt) whose $1^{\text {st }}$ to $4^{\text {th }}$ nucleotides were phosphothioated.

276 Preparation of symbiont-free nymphs by surface sterilization of eggs

277 Egg clutches produced by the stock culture of $P$. stali were soaked in 4\% formaldehyde for 10

$278 \mathrm{~min}$, rinsed with sterilized water several times, and kept in sterilized plastic boxes until use.

279 While this treatment does not affect hatchability and survival of the eggs, newborn nymphs fail

280 to acquire the symbiotic bacteria and become symbiont-free (33).

\section{Experimental evolution of P. stali-E. coli artificial symbiotic system}

283 Evolutionary experiments in this study consisted of, for each evolutionary P. stali line, (i) 284 preparation of an inoculum either from $E$. coli culture of $\Delta$ mutS or $\Delta$ intS (only G1) or from an 285 adult female of the previous generation (from G2 and on), (ii) oral administration of the 286 inoculum to symbiont-free nymphs, (iii) rearing of the nymphs either to their adulthood or death, 287 (iv) selection of an adult female for inoculation to the next generation, (iv) contamination check 288 of the selected adult female, (v) preparation of an inoculum and a glycerol stock from the symbiotic organ dissected from the selected female, and (vi) morphological measurements of all adult insects obtained.

Either diluted E. coli culture $\left(2.5 \mathrm{ml}\right.$ adjusted to $\left.\mathrm{OD}_{600}=0.1\right)$ or homogenate of the symbiotic organ dissected from a selected female of the previous generation $(2.5 \mathrm{ml}$ containing $1 / 2$ organ equivalent) was soaked in a cotton pad and orally administered to around 84 symbiont-free hatchlings derived from six surface-sterilized egg masses, by making use of the nymphal behavior that, after egg surface probing for about $30 \mathrm{~min}$ and resting for around a day, they take water without feeding and molt to second instar in a few days $(11,33)$. These nymphs were reared on sterilized peanuts, soybeans and ascorbic acid water as described previously (33). In the evolutionary experiments, two selection schemes, growth selection and color selection, were conducted (fig. S3). In growth selection lines (GmL for hyper-mutating $\Delta$ mutS lines; GiL for non-mutating $\Delta$ intS lines), the first-emerged adult female was subjected to dissection of the symbiotic organ for inoculation to the next generation as well as freeze storing. In color selection lines ( $\mathrm{CmL}$ for $\Delta$ mutS lines; $\mathrm{CiL}$ for $\Delta \mathrm{intS}$ lines), adult females were collected for 35 days after hatching or until at least one adult female emerged. These adult females were anesthetized on ice and photographed from the ventral side using a digital camera. Their body color was measured using the image analyzing software Natsumushi ver. 1.10 (34), and the adult female that exhibited the highest hue angle (= greenness) was subjected to dissection of 
the symbiotic organ for inoculation to the next generation as well as freeze storing.

The symbiotic organ of the selected female was dissected in PBS $(0.8 \% \mathrm{NaCl}, 0.02 \% \mathrm{KCl}$, $0.115 \% \mathrm{Na}_{2} \mathrm{HPO}_{4}, 0.02 \% \mathrm{KH}_{2} \mathrm{PO}_{4}, \mathrm{pH} 7.4$ ), rinsed with $70 \%$ ethanol, and homogenized in 200 $\mu \mathrm{L}$ sterile water. Of the $200 \mu \mathrm{L}$ homogenate, $5 \mu \mathrm{L}$ was used for contamination check by quantitative PCR. The number of E. coli genome copies was evaluated in terms of kanamycin resistance gene copies, which is present in the $\Delta$ intS and $\Delta$ mutS mutants but absent in wildtype E. coli and other bacteria. The number of total bacterial genome copies was evaluated based on bacterial 16S rRNA gene copies. When the former E. coli genome copy number was approximately the same as the latter bacterial genome copy number, the specimen was diagnosed as free of contamination. When the specimen was diagnosed as contaminated, the next best female was used. For quantitative PCR, the primers Tn5-1789F (5'-TGC TCG ACG TTG TCA CTG AA-3') and Tn5-1879R (5'-GCA GGA GCAAGG TGA GAT GA-3') were used for kanamycin resistance gene, while the primers 16S-967F (5'-CAA CGC GAA GAA CCT TAC C-3') and 16S-1046R (5'-CGA CAG CCA TGC ANC ACC T-3') were used for bacterial 16S rRNA gene. The PCR reaction was performed using Brilliant PCR mix (Agilent Technologies, USA). The standard curve was drawn using serially diluted $\Delta$ intS genomic DNA, which contains one kanamycin gene copy and seven 16S rRNA gene copies per genome. The thermal profile was the initial denaturation at $95^{\circ} \mathrm{C}$ for $3 \mathrm{~min}$ followed by 40 cycles of incubation at $95^{\circ} \mathrm{C}$ for $5 \mathrm{sec}$ and at $60^{\circ} \mathrm{C}$ for $10 \mathrm{sec}$. To confirm specific amplification, melting curve analysis was also included. The reaction was conducted on Mx3000p (Agilent Technologies, USA). While $100 \mu \mathrm{L}$ of the homogenate of the female symbiotic organ diagnosed as free of contamination was used as the inoculum to the next generation, the remaining homogenate $(\sim 95 \mu \mathrm{L})$ was mixed with an equal volume of $20 \%$ glycerol and stored at $-80^{\circ} \mathrm{C}$.

Inoculation of E. coli frozen stocks to P. stali

The frozen glycerol stocks were thawed, of which $50 \mathrm{~mL}$ was taken and diluted with sterile water to $3 \mathrm{~mL}$. Each of three replicates of around 84 symbiont-free hatchlings from six surfacesterilized egg masses was fed with $1 \mathrm{ml}$ inoculum soaked in a cotton pad as described above. The symbiont $\mathrm{A}$ and $\Delta$ mutS were included in the evaluation as positive and negative controls, respectively. Adult emergence of the insects was monitored for 50 days after hatching. All the adult insects were photographed from the dorsal side with a digital camera, and hue angle (= greenness) of the scutellum and thorax width were measured using ImageJ (35). For the subsequent RNA sequencing analyses and resequencing of $E$. coli genomes, the symbiotic organs were isolated from the adult insects and homogenized in $100 \mu \mathrm{L}$ PBS. Of $100 \mu \mathrm{L}$ homogenate, $50 \mu \mathrm{L}$ was subjected to RNA sequencing and the remaining $50 \mu \mathrm{L}$ was used for 
genome resequencing.

\section{$\underline{\text { RNA sequencing analyses }}$}

345 The homogenate of the symbiotic organ was subjected to total RNA extraction using RNAiso

346 (Takara Bio, Japan) and RNeasy Mini Kit (Qiagen, Nederland). Then, ribosomal RNAs of both 347 insect and bacterial origins were removed from the total RNA samples using Ribo-Zero Gold 348 rRNA Removal Kit (Epidemiology) (Illumina, USA). The rRNA-depleted RNAs were converted to paired end libraries using Sure Select Strand Specific RNA Kit (Agilent Technologies, USA) or TruSeq RNA Library Prep Kit v2 (Illumina, USA) (see table S1). The libraries were sequenced with Hiseq 3000 or Hiseq X (Illumina, USA).

The obtained sequences were trimmed, mapped to E. coli BW25113 genome sequence (Accession number NZ_CP009273), and read-counted with CLC Genomics Workbench 10.0 (Qiagen, Germany). Normalizations and differential expression analyses were conducted with EdgeR ver. 3.32.1 (36). Complex Heatmap ver. 2.10.0 (37) was used for clustering analyses and drawing heatmaps of the RNA sequencing libraries.

Genome resequencing and detection of structural changes

359 DNA samples were extracted from the homogenates of the symbiotic organ using QIAamp DNA Mini Kit (Qiagen, Germany). The extracted DNAs were converted to paired end libraries using Nextera XT DNA Library Prep Kit (Illumina, USA) and the libraries were sequenced with Miseq (Illumina, USA). CLC Genomic Workbench ver. 10.0 was used for detection of $E$. coli genome variants that emerged during the evolutionary experiments. The heatmaps of the variant frequency data were drawn using Complex Heatmap (37).

Fluorescence in situ hybridization

367 Fluorescence in situ hybridization (FISH) analyses were performed essentially as described (38). The whole insect bodies or isolated digestive tracts were fixed with PBS containing $4 \%$ formaldehyde (Fujifilm, Japan). The fixed samples were embedded in Technovit 8100 (Kulzer, Germany) and processed into $2 \mu \mathrm{m}$ tissue sections using a rotary microtome RM2255 (Leica, Germany). The AlexaFluor555-labeled oligonucleotide probes Eco934 (5'-CAT GCT CCA CCG CTT GTG-3') and SymAC89R (5'-GCA AGC TCT TCT GTG CTG CC-3') were used to detect E. coli and the symbiont A, respectively (12). Host nuclei were counterstained with 4', 6-diamidino-2-phenylindole (DAPI) (Dojindo, Japan). The hybridized specimens were observed using a fluorescence dissection microscope M165FC (Leica, Germany), an epifluorescence microscope DM6B (Leica, Germany), and a laser confocal microscope 


\section{Infection of E. coli mutants and effects on host phenotypes}

380 E. coli mutants were cultured, diluted, and orally administrated to symbiont-free newborn nymphs of $P$. stali as described above. The insects were reared to monitor their adult emergence for 42 days after hatching. The dorsal images of the adults were taken with an image scanner GT-X830 (Epson, Japan), and the hue angle of the scutellum and thorax width were measured and analyzed using the software Natsumushi (34). P. stali harboring the original symbiont Pantoea sp. A was also included as a reference. As for the adult females infected with E. coli, bacterial titers in the symbiotic organs were measured by quantitative PCR. KAPA SYBR Fast qPCR Kit (Roche, USA), Tn5-1789F and Tn5-1879R primer sets were used for quantification. The standard curves were drawn using serially diluted pT7Blue (Takara Bio, Japan) plasmid carrying a kanamycin resistance gene fragment. The quantitative PCR reactions were conducted on Light Cycler 96 (Roche, Switzerland).

\section{Measurement of $E$. coli phenotypes}

393 For inspection of colony morphology and extracellular matrix production, E. coli cultures were spread onto LB agar plates containing $80 \mu \mathrm{g} / \mathrm{mL}$ Congo Red (Merck, USA) and incubated at $25^{\circ} \mathrm{C}$ for 3 days. Colonies formed on the plate were photographed by using a scanner GT-X850 and/or dissection microscope S9i (Leica, Germany).

For growth curve measurements, each glycerol stock of $E$. coli was inoculated to $2 \mathrm{~mL}$ LB broth (Becton Dickinson, USA) and incubated at $25^{\circ} \mathrm{C}$ for $16 \mathrm{~h}$ with shaking at $200 \mathrm{rpm}$. The cell culture was diluted to $\mathrm{OD}_{600}=0.005$ in $25 \mathrm{~mL} \mathrm{LB}$ broth, and incubated at $25^{\circ} \mathrm{C}$ with shaking at $200 \mathrm{rpm}$. From the bacterial culture, $120 \mu \mathrm{L}$ of cell suspension was sampled every hour, and the samples were subjected to measurement of $\mathrm{OD}_{600}$ using a spectrometer UV-1800 (Shimadzu, Japan).

For time-lapse analyses of growth and morphology of individual E. coli cells, two types of microfluidic devices were used. One type was a microfluidic device in which bacterial cells were enclosed in microchambers etched on a glass coverslip. A cellulose membrane was attached to a coverslip via biotin-streptavidin binding, on which the microchambers were fabricated as described previously $(39,40)$. Another type was a microfluidic device made of polydimethylolefin (PDMS) with a channel structure similar to Mother Machine 3 as described previously (41) (see fig. S6f). The width of the cell observation channels in this device was 9 $\mu \mathrm{m}$, which was broader than that of the Mother Machine and thus each cell observation channel could harbor 30-70 individual E. coli cells depending on cell sizes. E. coli cells in exponential 
412 phase were introduced into both types of the microfluidic devices and observed under a Nikon 413 Ti-E microscope (Nikon, Japan) equipped with ORCA-fusion camera (Hamamatsu Photonics, 414 Japan). In the time-lapse measurements, phase-contrast images were acquired with a $100 \times$ oil 415 immersion objective lens (Plan Apol, NA 1.45) at an interval of $3 \mathrm{~min}$, in which 50-100 XY 416 positions were simultaneously observed. The microscope was controlled from a computer using 417 Micromanager 4. In the microchamber device measurements, LB broth was supplemented with $4180.1 \%$ bovine serum albumin and $0.02 \%$ Tween- 80 to suppress cell adhesion, and introduced 419 into the devices at a flow rate of $2 \mathrm{~mL} / \mathrm{h}$.

420 For measurements of size and flagellar motility, E. coli cells were grown in LB medium 421 with shaking at $25^{\circ} \mathrm{C}$ to around $\mathrm{OD}_{600}=2.0$, observed under a phase-contrast microscope IX71 422 (Olympus, Japan), recorded by a CCD camera DMK33UP5000.WG (The Imaging Source, 423 Germany) at 30 frames per second, and analyzed using ImageJ v1.53 (35) and IGOR Pro 8.02 J (WaveMetrics, USA). The cell size data were measured for individual six cultures. The swimming ratio data were obtained as the number of swimming cells in 100 cells from individual eight cultures.

Statistics

Statistical analyses were conducted by using R ver. 4.1.2 (42) and RStudio (43). R was also used to plot the data.

\section{References}

1. McFall-Ngai, M. et al. Animals in a bacterial world, a new imperative for the life sciences. Proc. Natl. Acad. Sci. USA 110, 3229-3236 (2013).

2. Gilbert, S. F., Bosch, T. C. G. \& Ledón-Rettig, C. Eco-Evo-Devo: developmental symbiosis and developmental plasticity as evolutionary agents. Nat. Rev. Genet. 16, 611-622 (2015).

3. Hoang, K. L., Morran, L. T. \& Gerardo, N. M. Experimental evolution as an underutilized tool for studying beneficial animal-microbe interactions. Front. Microbiol. 7, 1444 (2016).

4. King, K. C. et al. Rapid evolution of microbe-mediated protection against pathogens in a worm host. ISME J. 10, 1915-1924 (2016).

5. Tso, G. H. W. et al. Experimental evolution of a fungal pathogen into a gut symbiont. Science 362, 589-595 (2018).

6. Robinson, C. D. et al. Experimental bacterial adaptation to the zebrafish gut reveals a primary role for immigration PLoS Biol. 16, e2006893 (2018).

7. Mehta, A. P. et al. Engineering yeast endosymbionts as a step toward the evolution of mitochondria. Proc. Natl. Acad. Sci. USA 115, 11769-11801 (2018). 
8. Drew, G. C., EJ Stevens, E. J. \& King, K. C. Microbial evolution and transitions along the parasite-mutualist continuum. Nat. Rev. Microbiol. 19, 623-638 (2021).

9. Nikoh, N. et al. Reductive evolution of bacterial genome in insect gut environment. Genome Biol. Evol. 3, 702-714 (2011).

10. Salem, H. et al. Vitamin supplementation by gut symbionts ensures metabolic homeostasis in an insect host. Proc. R. Soc. B 281, 20141838 (2014).

11. Hosokawa, T. et al. Obligate bacterial mutualists evolving from environmental bacteria in natural insect populations. Nat. Microbiol. 1, 15011 (2016).

12. Oishi, S. et al. Morphogenesis and development of midgut symbiotic organ of the stinkbug Plautia stali (Hemiptera: Pentatomidae). Zool. Let. 5, 16 (2019).

13. Hosokawa T. et al. Recurrent evolution of gut symbiotic bacteria in pentatomid stinkbugs. Zool. Let. 2, 34 (2016).

14. Otero-Bravo, A. \& Sabree, Z. L. Multiple concurrent and convergent stages of genome reduction in bacterial symbionts across a stink bug family. Sci. Rep. 11, 7731 (2021).

15. Giraud, A. et al. Costs and benefits of high mutation rates: adaptive evolution of bacteria in the mouse gut. Science 291, 2606-2608 (2001).

16. Deutscher, J. et al. How phosphotransferase system-related protein phosphorylation regulates carbohydrate metabolism in bacteria. Microbiol. Mol. Biol. Rev. 70, 939-1031 (2006).

17. Görke, B. \& Stülke, J. Carbon catabolite repression in bacteria: many ways to make the most out of nutrients Nat. Rev. Microbiol. 6, 613-624 (2008).

18. Martinez-Antonio, A. \& Collado-Vides, J. Identifying global regulators in transcriptional regulatory networks in bacteria. Curr. Opin. Microbiol. 6, 482-489 (2003).

19. Zheng, D. et al. Identification of the CRP regulon using in vitro and in vivo transcriptional profiling. Nucleic Acids Res. 32, 5874-5893 (2004).

20. Santos-Zavaleta, A. et al. RegulonDB v 10.5: tackling challenges to unify classic and high throughput knowledge of gene regulation in E. coli K-12. Nucleic Acids Res. 47, D212D220 (2019).

21. Shimada, T. et al. Novel roles of cAMP receptor protein (CRP) in regulation of transport and metabolism of carbon sources. PLoS One 6, e20081 (2011).

22. Xavier, K. B. \& Bassler, B. L. Regulation of uptake and processing of the quorum-sensing autoinducer AI-2 in Escherichia coli. J. Bacteriol. 187, 238-248 (2005).

23. Müller, C. M. et al. Type 1 fimbriae, a colonization factor of uropathogenic Escherichia coli, are controlled by the metabolic sensor CRP-cAMP. PLoS Pathog. 5, 1000303 (2009). 24. McCutcheon, J. P. \& Moran, N. A. Extreme genome reduction in symbiotic bacteria. Nat. 
Rev. Microbiol. 10, 13-26 (2012).

25. Moran, N. A. et al. Regulation of transcription in a reduced bacterial genome: nutrientprovisioning genes of the obligate symbiont Buchnera aphidicola. J. Bacteriol. 187, 42294237 (2005).

26. Blount, Z. D. The unexhausted potential of E. coli. eLife 4, e05826 (2015).

27. Baba, T. et al. Construction of Escherichia coli K-12 in-frame, single-gene knockout mutants: the Keio collection. Mol. Syst. Biol. 2, 2006.0008 (2006).

28. Tenaillon, O. et al. The population genetics of commensal Escherichia coli. Nat. Rev. Microbiol. 8, 207-217 (2010).

29. Giraud, A. et al. Dissecting the genetic components of adaptation of Escherichia coli to the mouse gut. PLoS Genet. 4, e2 (2019).

30. Barroso-Batista, J. et al. Specific eco-evolutionary contexts in the mouse gut reveal Escherichia coli metabolic versatility. Curr. Biol. 30, 1049-1062.e7 (2020).

31. Datsenko, K. A. \& Wanner, B. L. One-step inactivation of chromosomal genes in Escherichia coli K-12 using PCR products. Proc. Natl. Acad. Sci. USA 97, 6640-6645 (2000).

32. Nyerges Á., et al. A highly precise and portable genome engineering method allows comparison of mutational effects across bacterial species. Proc. Natl. Acad. Sci. USA 113, 2502-2507 (2016).

33. Nishide, Y., et al. Aseptic rearing procedure for the stinkbug Plautia stali (Hemiptera: Pentatomidae) by sterilizing food-derived bacterial contaminants. Appl. Entomol. Zool. 53, 407-415 (2017).

34. Tanahashi, M. \& Fukatsu, T. Natsumushi - Image measuring software for entomological studies. Entomol. Sci. 21, 347-360 (2018).

35. Schneider, C. A., Rasband, W. S. \& Eliceiri, K. W. NIH Image to ImageJ: 25 years of image analysis. Nat. Methods 9, 671-675 (2012).

36. Robinson, M. D., McCarthy, D. J. \& Smyth, G. K. EdgeR: a Bioconductor package for differential expression analysis of digital gene expression data. Bioinformatics 26, 139-140 (2010).

37. Gu, Z., Eils, R. \& Schlesner, M. Complex heatmaps reveal patterns and correlations in multidimensional genomic data. Bioinformatics 32, 2847-2849 (2016).

38. Koga, R., Tsuchida, T. \& Fukatsu, T. Quenching autofluorescence of insect tissues for in situ detection of endosymbionts. Appl. Entomol. Zool. 44, 281-291 (2009).

39. Inoue, I., Wakamoto, Y., Moriguchi, H., Okano, K. \& Yasuda, K. On-chip culture system for observation of isolated individual cells. Lab. Chip 1, 50-55 (2001). 
40. Hashimoto, M., et al. Noise-driven growth rate gain in clonal cellular populations. Proc. Natl. Acad. Sci. USA 113, 3251-3256 (2016).

41. Wang, P., et al., Robust growth of Escherichia coli. Curr. Biol. 20, 1099-1103 (2010).

42. R Core Team. R: A language and environment for statistical computing. R Foundation for Statistical Computing, Vienna, Austria (2021). https://www.R-project.org/

43. RStudio Team. RStudio: Integrated Development Environment for R (2020). http://www.rstudio.com/

44. Hayashi, T., et al. Female-specific specialization of a posterior end region of the midgut symbiotic organ in Plautia splendens and allied stinkbugs. Appl. Environ. Microbiol. 81,

\section{Acknowledgments}

529 We thank U. Asaga, S. Kimura, J. Makino and T. Matsushita for insect rearing and technical 530 assistance. This study was supported by the JST ERATO grants JPMJER1803 and 531 JPMJER1902 (TF, CF, YW, RK) and the JSPS KAKENHI grant JP25221107 (TF, RK).

532 Genome sequencing and analyses were supported by the JSPS KAKENHI grant JP16H06279.

Author contributions: RK and TF conceived the project and designed the experiments. RK, HT, YN and THo analyzed insect phenotypes, RK, MMi, KO, RO and YW analyzed E. coli phenotypes, RK, MMo, NOT, YG and THa performed genome sequencing and analyses, MMo, RK, NOT, MS and YS conducted RNA sequencing and analyses, RK, HT, SS and CF designed and generated hyper-mutating and other E. coli strains, and TF wrote the manuscript with input from all the other authors.

\section{Competing interests}

543 The authors declare no competing interests.

\section{Data and materials availability}

546 All RNA sequencing and DNA sequencing data produced in this study were deposited in DDBJ

547 Sequence Read Archive (DRA) (see tables S1 and S5). All data are available in the manuscript 548 or the supplementary materials. 
551 Fig. 1. Infection, localization and vertical transmission of $E$. coli in the gut symbiotic

552 system of $\boldsymbol{P}$. stali. (a) Normal symbiotic adult female, large in size and green in color. (b)

553 Dissected alimentary tract, in which symbiotic organ is well developed and yellow in color. (c)

554 Fluorescence in situ hybridization (FISH) localization of symbiont cells to the symbiotic organ.

555 (d) Magnified FISH image showing symbiont localization to crypt cavities of the symbiotic

556 organ. (e) Adult emergence rates of newborn nymphs inoculated with normal symbiont (Sym,

557 Pantoea sp. A), no bacteria (Apo, aposymbiotic), and E. coli. (f) Symbiont cells smeared on

558 egg surface. (g) Newborn nymphs sucking symbiont cells from eggshell. (h) E. coli-infected

559 adult female, dwarf in size and brown in color. (i) Dissected alimentary tract, in which

560 symbiotic organ is atrophied. (j) FISH localization of E. coli to the symbiotic organ. (k)

561 Magnified FISH image visualizing E. coli localization to crypt cavities of the symbiotic organ.

562 (l) Bacterial titers in symbiont-inoculated and E. coli-inoculated nymphs one day after second

563 instar molt in terms of groEL and nptII gene copies per insect, respectively. (m) E. coli cells

564 smeared on egg surface.

565 
bioRxiv preprint doi: https://doi.org/10.1101/2022.0126.477692; this version posted January 28, 2022. The copyright holder for this preprint (which was not certified by peer review) is the author/funder, who has granted bioRxiv a license to display the preprint in perpetuity. It is made available under aCC-BY-NC-ND 4.0 International license.
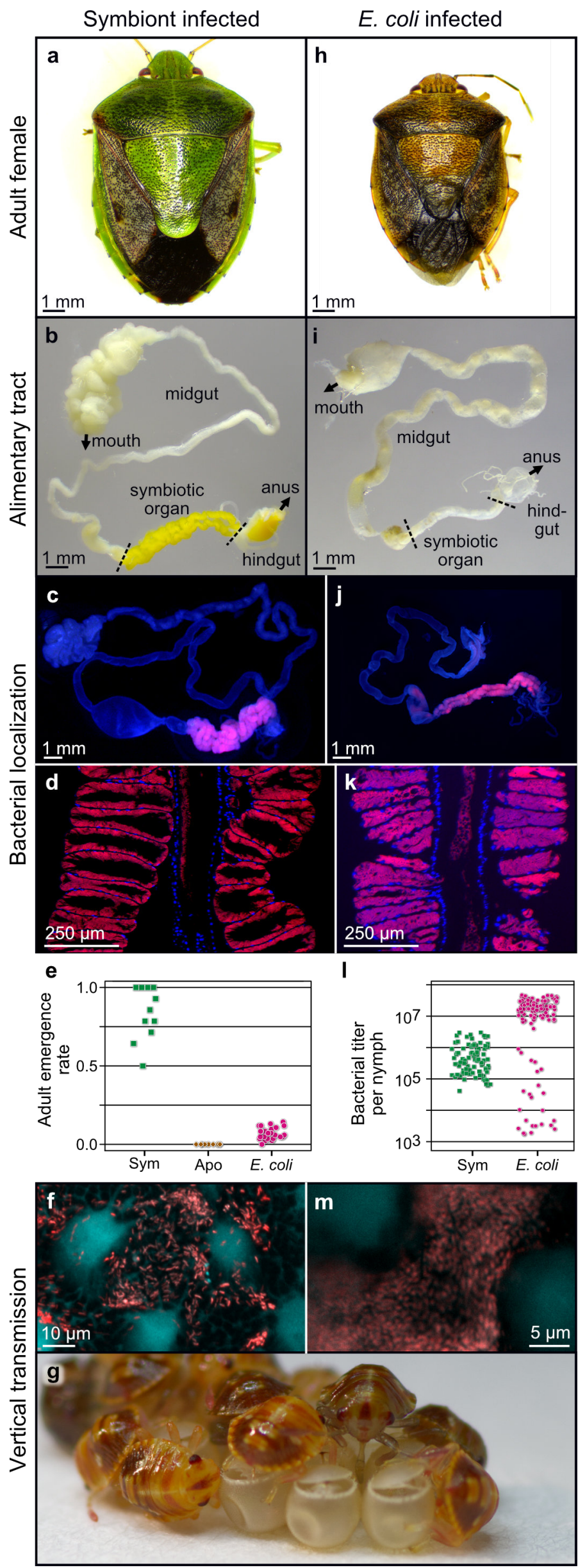

Fig. 1 
570 Fig. 2. Evolution of mutualistic traits for $\boldsymbol{P}$. stali in hyper-mutating $\boldsymbol{E}$. coli lines. (a)

571 Evolutionary E. coli lines subjected to host's body color selection. Data of adult emergence rate

572 and body color are displayed by heat maps. White asterisks indicate missing data of body color

573 measurement. (b) Evolutionary E. coli lines subjected to host's growth speed selection. Data of

574 adult emergence rate and days to the first adult emergence are displayed by heat maps. Note

575 that in (a) and (b), when an evolutionary line produced no adult insect and recovery from the

576 freeze stock failed twice consecutively, the evolutionary line was terminated due to shortage of

577 inoculum. From generation 10 and on, selected evolutionary lines were maintained. (c) Host's

578 body color and colony morphology of evolutionary E. coli lines. Red colonies are due to rich

579 extracellular matrix produced on the agar plates containing Congo red. (d, e) Adult emergence

580 patterns of $P$. stali infected with the representative E. coli lines, CmL05, GmL07, GmL02 and

$581 \mathrm{GmL04}$, in the original evolutionary experiments (d) and those in the confirmation experiments

582 using frozen E. coli stocks (e). In (c)-(e), magenta lines and blue lines highlight "improved"

583 generations and "non-improved" generations, respectively. 
bioRxiv preprint doi: https://doi. org/10.1101/2022 01 26.477692; this version posted January 28, 2022. The copyright holder for this preprint (which was not certified by peer review) is the author/funder, who has granted bioRxiv a license to display the preprint in perpetuity. It is made available under aCC-BY-NC-ND 4.0 International license.

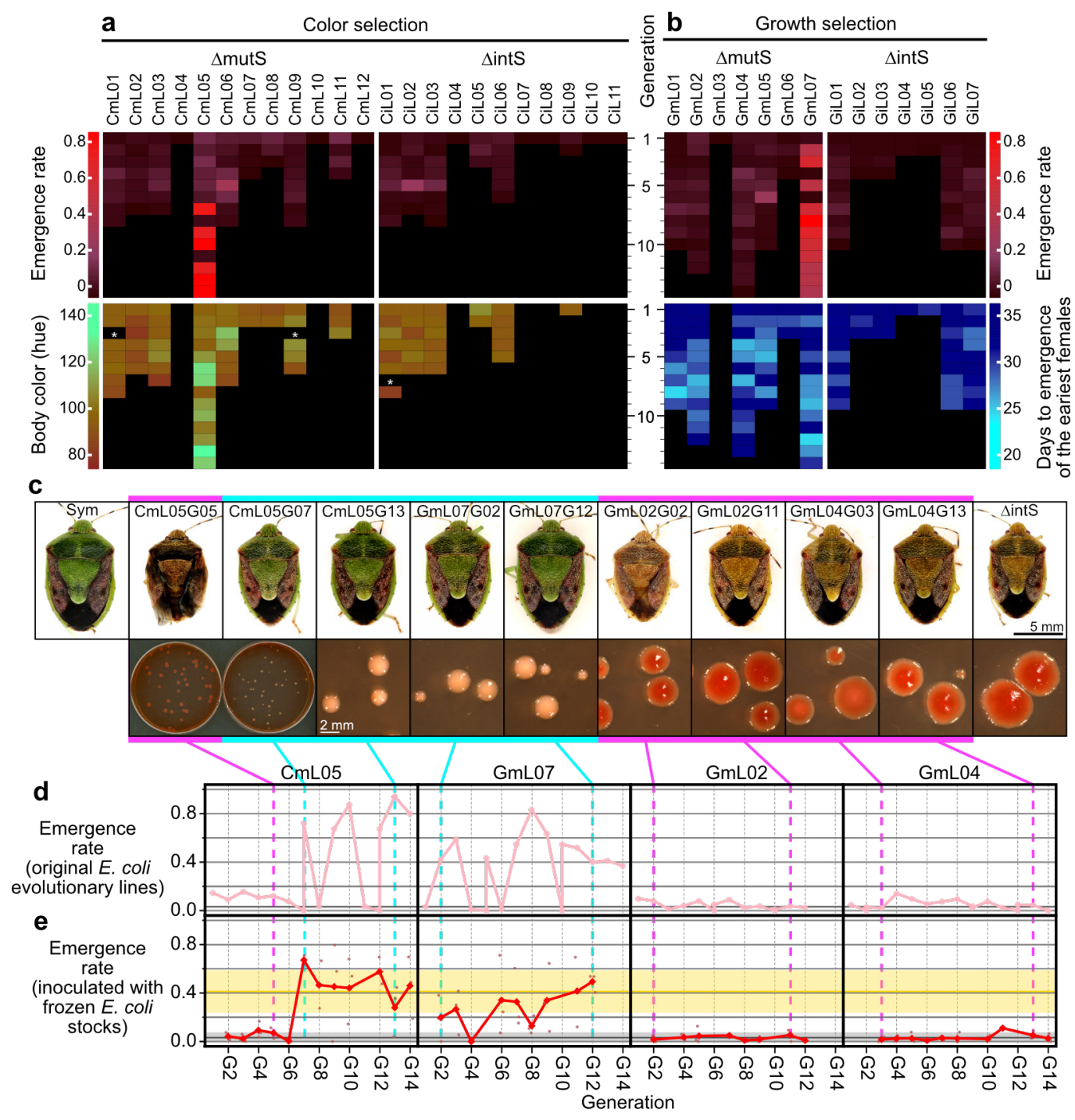

Fig. 2 
590 Fig. 3. Transcriptomics and genomics of evolutionary $E$. coli lines. (a, b) Clustering

591 dendrograms and heatmaps based on gene expression levels across generations of evolutionary

592 E. coli lines subjected to color selection (right, 3,401 genes) (a) and growth selection (left,

593 3,360 genes) (b). Gray and colored areas depict non-improved and improved generations,

594 respectively. (c) Mutations identified in the genomes of CmL05 and GmL07 as coincident with

595 the improvement of host phenotypes. (d) Candidate mutations disrupting the catabolite

596 repression pathway: a frame shift mutation in cyaA of CmL05 (top) and a non-synonymous

597 mutation causing change from leucine to proline at a functionally important cAMP binding

598 domain in crp of GmL07 (bottom). (e) Schematic presentation as to how CRP pathway is

599 disrupted by the cyaA and crp mutations.

600

601 
bioRxiv preprint doi: https://doi org/10.1101/2022.0126.477692; this version posted January 28, 2022. The copyright holder for this preprint (which was not certified by peer review) is the author/funder, who has granted bioRxiv a license to display the preprint in perpetuity. It is made available under aCC-BY-NC-ND 4.0 International license.

a Color selection (CmL05)

b Growth selection (GmL02, 04 and 07)

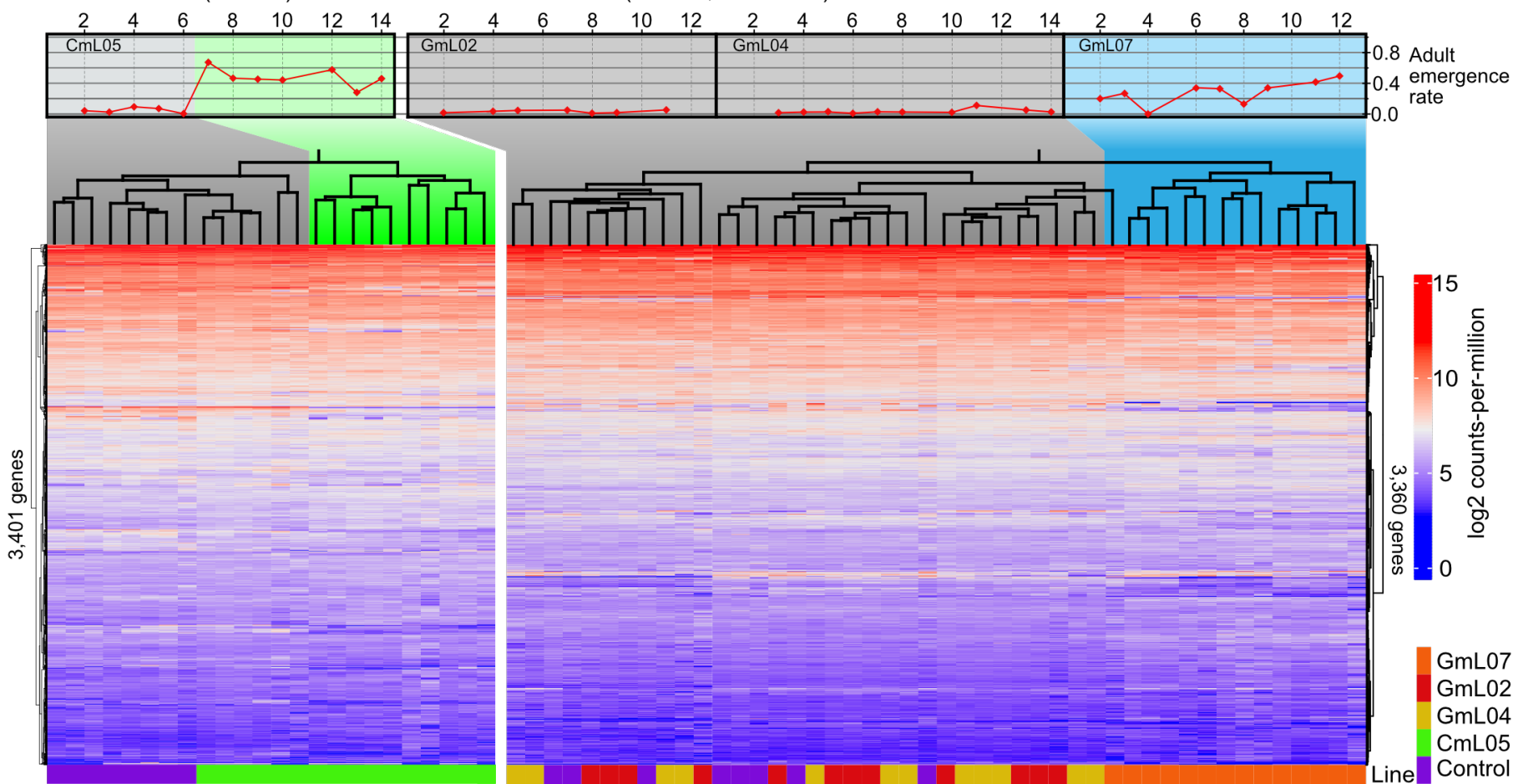

C

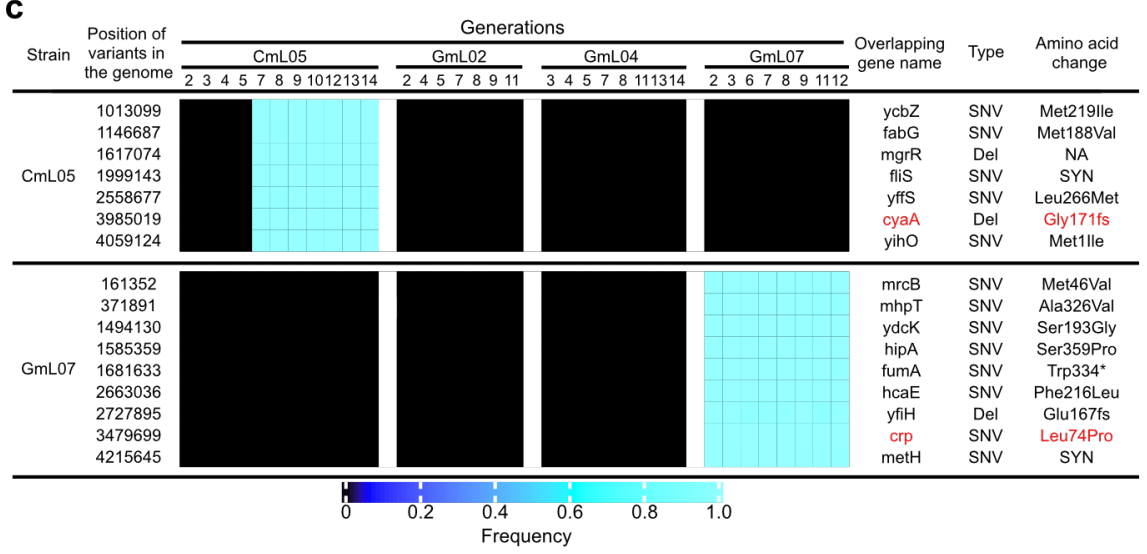

d

cyaA $^{507 d e l G}$

Adenylate cyclase class- 1

$\mathrm{N}$-terminal domain $-1, \quad$ Adenylate cyclase class-1

Frame shift mutation

$(\triangle$ cyaA $)$

$\operatorname{crp}^{221 T>C}$
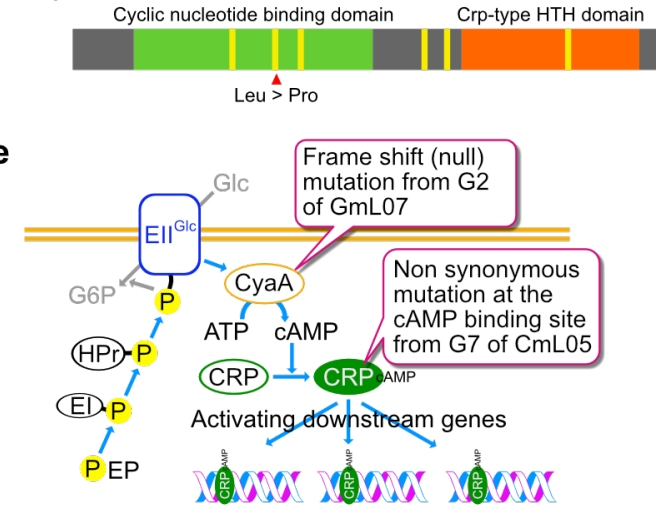

Fig. 3 
605 Fig. 4. Single mutations disrupting carbon catabolite repression pathway make $E$. coli

606 mutualistic to $P$. stali. (a) Small, convex and white colonies of $\Delta$ cyaA and $\operatorname{crp}^{221 \mathrm{~T}>\mathrm{C}}$. (b) Adult 607 emergence rates of $P$. stali infected with $\Delta$ cyaA and $\operatorname{crp}^{221 \mathrm{~T}>\mathrm{C}}$. Different alphabetical letters 608 indicate statistically significant differences (pairwise Wilcoxon rank sum test with Bonferroni 609 correction: $P<0.05$ ). (c) Adult insects infected with $\Delta$ cyaA and $\operatorname{crp}^{221 \mathrm{~T}>\mathrm{C}}$, which are larger in 610 size and green in color in comparison with those infected with control $\Delta$ intS. 
bioRxiv preprint doi: https://doi org/10.1101/2022.01.26.477692; this version posted January 28, 2022. The copyright holder for this preprint (which was not certified by peer review) is the author/funder, who has granted bioRxiv a license to display the preprint in perpetuity. It is made available under aCC-BY-NC-ND 4.0 International license.

a $\quad$ White $=\Delta$ cyaA $\quad$ Red $=\Delta$ intS White $=\operatorname{crp}^{221 T}>C \quad$ Red $=\Delta$ intS

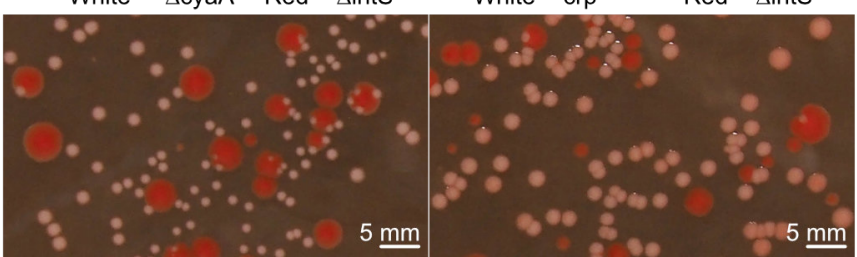

b
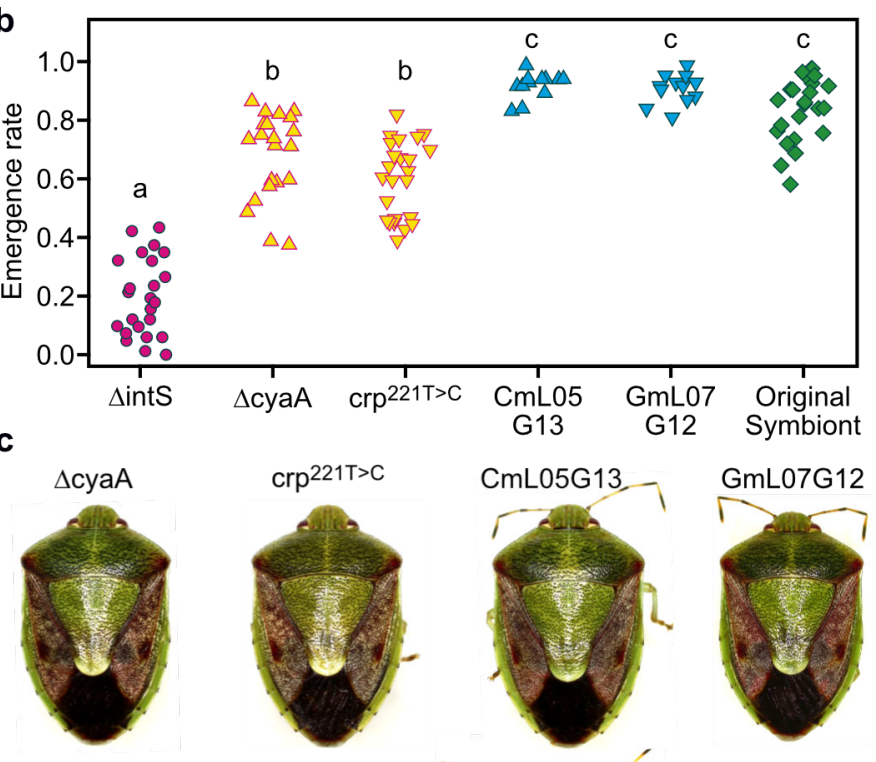

CmL05G13

GmL07G12
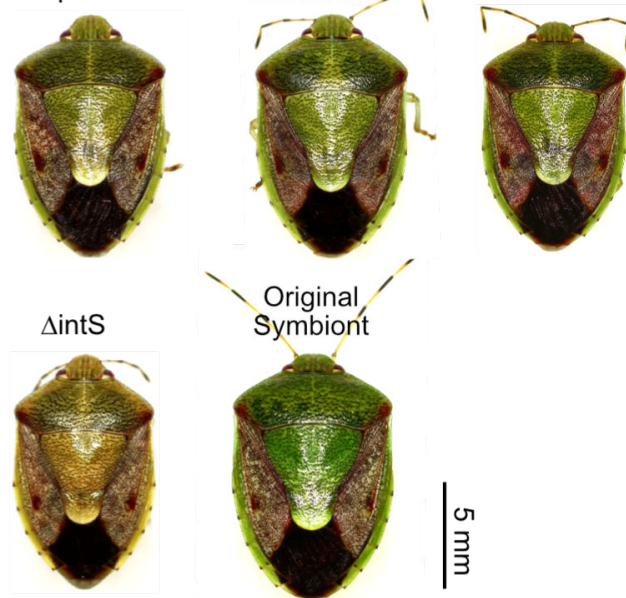

r

Fig. 4 
616 Fig. S1. Phenotypes of $\boldsymbol{P}$. stali adults infected with laboratory strains of $\boldsymbol{E}$. coli. (a) Adult

617 emergence rate. (b) Body color (greenish hue) of females (left) and males (right). (c) Body size

618 (thorax width) of females (left) and males (right). Sym A is Pantoea sp. A, the original,

619 uncultivable and essential gut symbiont of P. stali (11). BW25113, EPI300, DH5a, JM109 and

620 BL21 are commonly used laboratory strains of E. coli.

621

622 
bioRxiv preprint doi: https://doi.org/10.1101/2022.01.26.477692; this version posted January 28, 2022. The copyright holder for this preprint (which was not certified by peer review) is the author/funder, who has granted bioRxiv a license to display the preprint in perpetuity. It is made available under aCC-BY-NC-ND 4.0 International license.

(a)

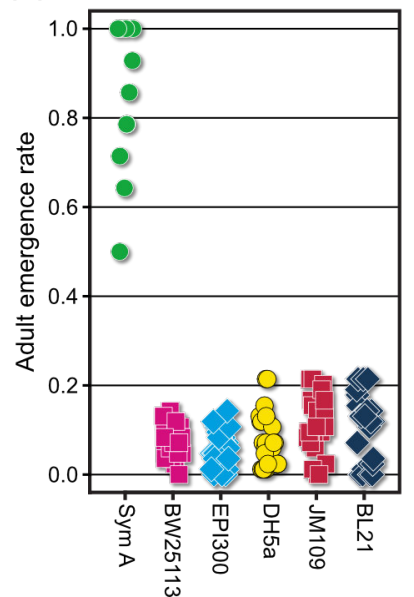

(b)

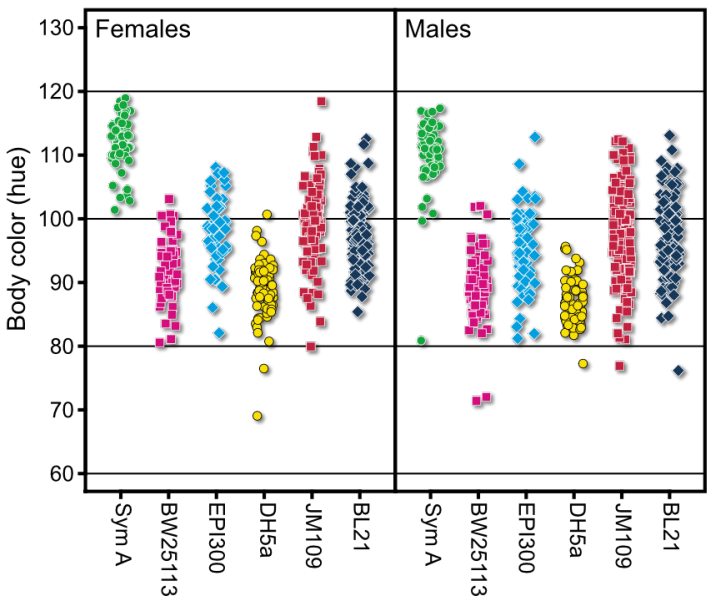

(c)

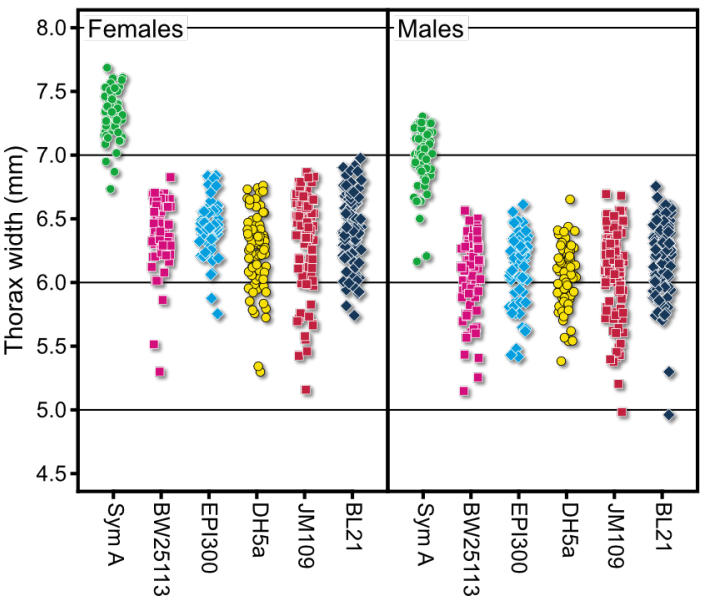


626 Fig. S2. FISH localization of $E$. coli and original symbiont Pantoea sp. A (= Sym A) in $P$.

627 stali. (a-d) Localization in abdominal body cavity of adult insects: (a) E. coli in adult female,

628 (b) Sym A in adult female, (c) E. coli in adult male, and (d) Sym A in adult male. FISH signals

629 are localized to the midgut M4 region. Signals in oocytes are due to autofluorescence.

630 Abbreviations: M1, M2, M3, and M4, midgut regions M1, M2, M3, and M4 (= symbiotic

631 organ); ov, ovary. (e, f) Localization of E. coli (e) and Sym A (f) in dissected alimentary tract

632 of adult females. Arrowheads indicate female-specific enlarged end crypts at the posterior end

633 of the symbiotic organ, which are presumably involved in vertical symbiont transmission by

634 storing bacteria-containing secretion (44). (g, h) Magnified images of the end crypts infected

635 with $E$. coli $(\mathbf{g})$ and Sym A (h). Note that E. coli-infected end crypts are atrophied in comparison

636 with Sym A-infected ones. (i, j) Localization of E. coli (i) and Sym A (j) in the crypt cavities

637 of the symbiotic organ. (k, l) Magnified images of E. coli cells (k) and Sym A cells (l) packed

638 in the crypt cavity. (m, n) Patchy localization patterns of E. coli in the symbiotic organ, which

639 are often found with E. coli but seldom observed with Sym A. 


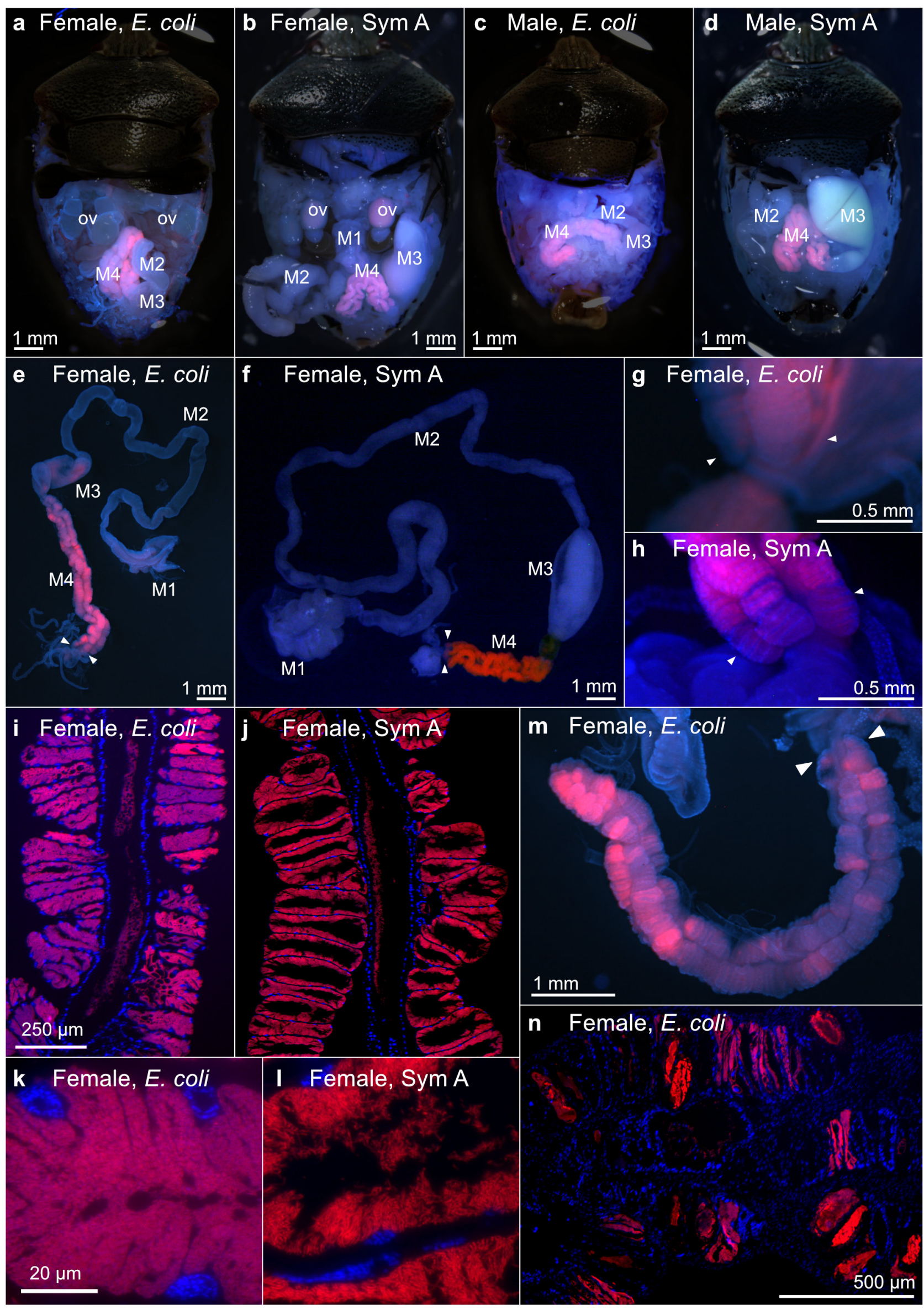


bioRxiv preprint doi: https://doi.org/10.1101/2022.01.26.477692; this version posted January 28, 2022. The copyright holder for this preprint (which was not certified by peer review) is the author/funder, who has granted bioRxiv a license to display the preprint in perpetuity. It is made available under aCC-BY-NC-ND 4.0 International license.

645 Fig. S3. Experimental scheme for evolution of mutualistic $E$. coli with $P$. stali.

646

647 
bioRxiv preprint doi: $\mathrm{https}$ //doi.org/10.1101/2022.01.26.477692; this version posted January 28, 2022. The copyright holder for this preprint (which was not certified by peer review) is the author/funder, who has granted bioRxiv a license to display the preprint in perpetuity. It is made available under aCC-BY-NC-ND 4.0 International license.

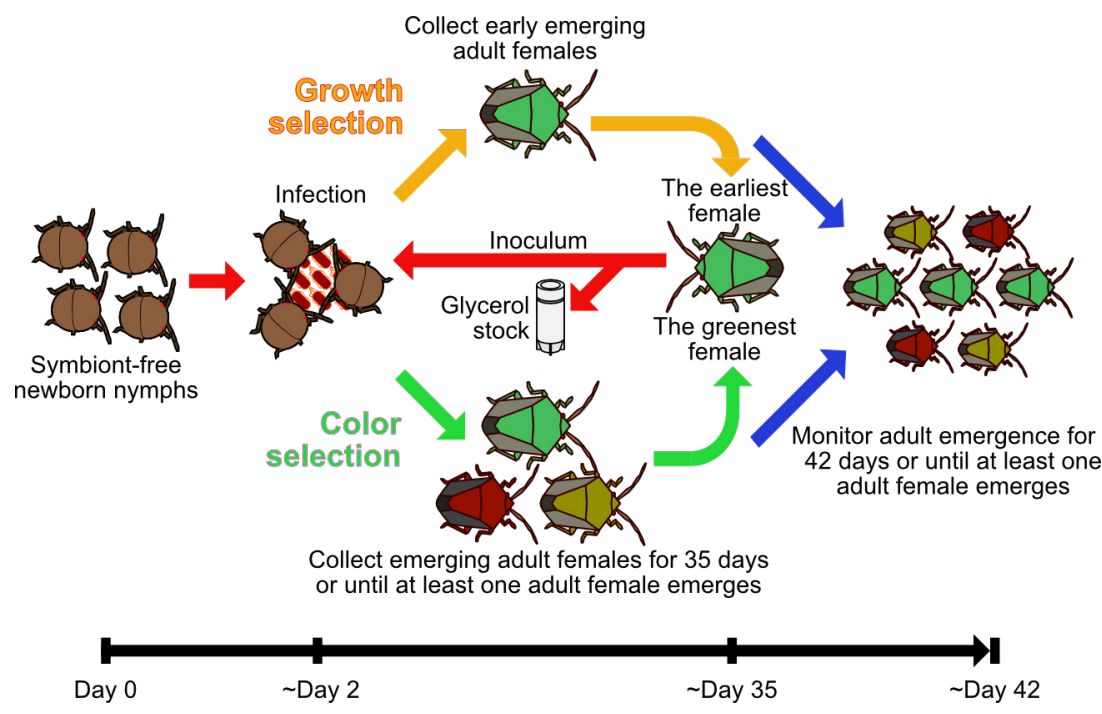


651 Fig. S4. Effects of evolutionary $E$. coli lines on body size and color of $P$. stali. (a)

652 Evolutionary E. coli lines subjected to host's body color selection. Data of host's body width

653 are displayed by heat maps. Also see Fig. 2a. (b) Evolutionary E. coli lines subjected to host's

654 growth speed selection. Data of host's body width and color are displayed by heat maps. Also

655 see Fig. 2b.

656

657 
bioRxiv preprint doi: https://doi org/10.1101/2022.01.26.477692; this version posted January 28, 2022. The copyright holder for this preprint (which was not certified by peer review) is the author/funder, who has granted bioRxiv a license to display the preprint in perpetuity. It is made available under aCC-BY-NC-ND 4.0 International license.

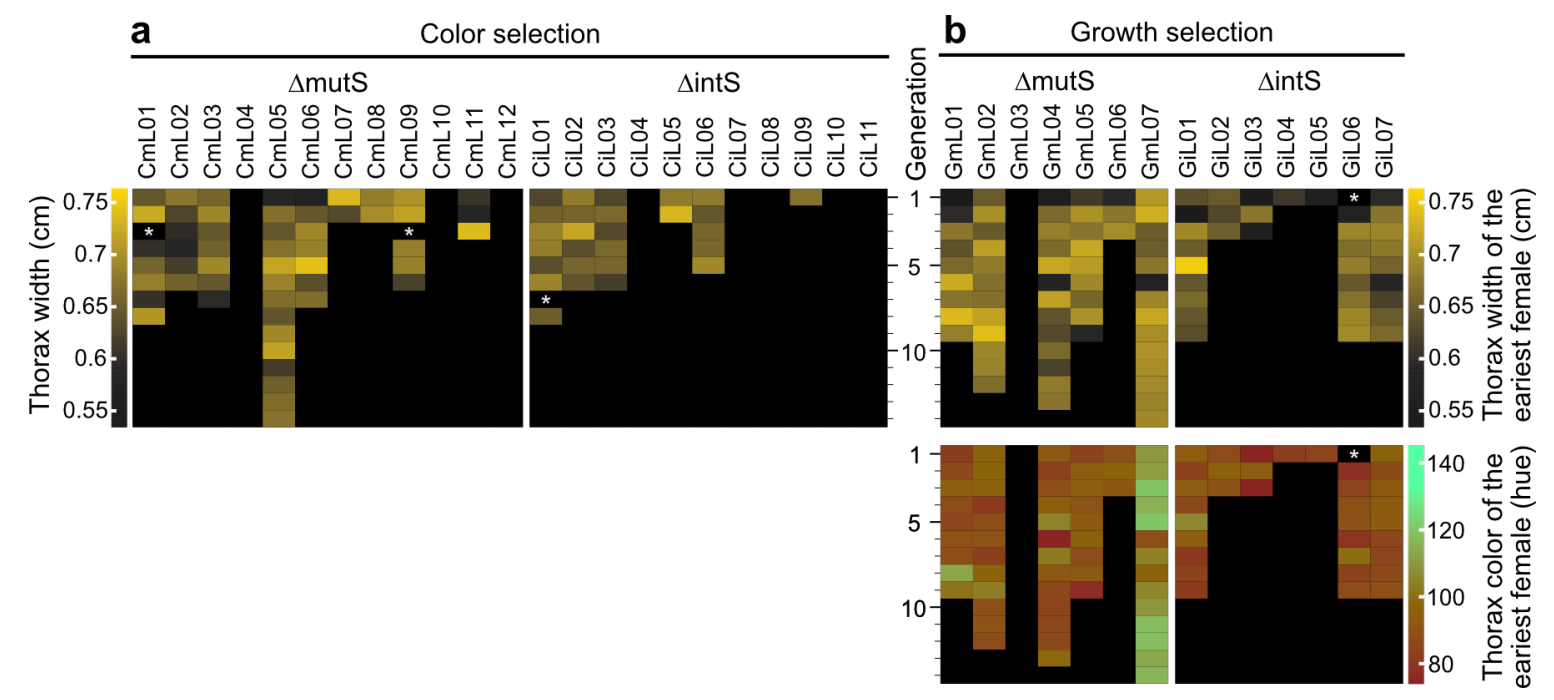


661 Fig. S5. Adult phenotypes of $P$. stali infected with the evolutionary $E$. coli lines CmL05,

662 GmL07, GmL02 and GmL04. (a, b) Nymphal period. (c, d) Nymphal period of the earliest

663 adult females. (e, f) Body color. (g, h) Thorax width. (a, c, e, g) Phenotypes of adult insects

664 infected with the original evolutionary E. coli lines. (b, d, f, h) Phenotypes of adult insects

665 inoculated with the frozen E. coli stocks. Line charts show mean values while dots indicate

666 individual data points. Note that, corresponding to each original evolutionary E. coli line, three

667 insect groups were inoculated with the frozen E. coli stock.

668

669

670 
bioRxiv preprint doi: https://doi.org/10.1101/2022.01.26.477692; this version posted January 28, 2022. The copyright holder for this preprint (which was not certified by peer review) is the author/funder, who has granted bioRxiv a license to display the preprint in perpetuity. It is made available under aCC-BY-NC-ND 4.0 International license.

a

Nymphal period (original evolutionary E. coli lines) (days)

b

Nymphal period (inoculated with frozen E. coli stocks) (days)

c

Nymphal period of the earliest adult females (original evolutionary E. coli lines) (days)

d

Nymphal period of the earliest adult females (inoculated with frozen

E. coli stocks) (days)

e

Body color

(original evolutionary E. coli lines (Hue)

f

Body color Body color
(inoculated with frozen E. coli stocks) (Hue)

g

Thorax width (original evolutionary E. coli lines) (cm)

h

Thorax width (inoculated with frozen

E. coli stocks)

(cm)

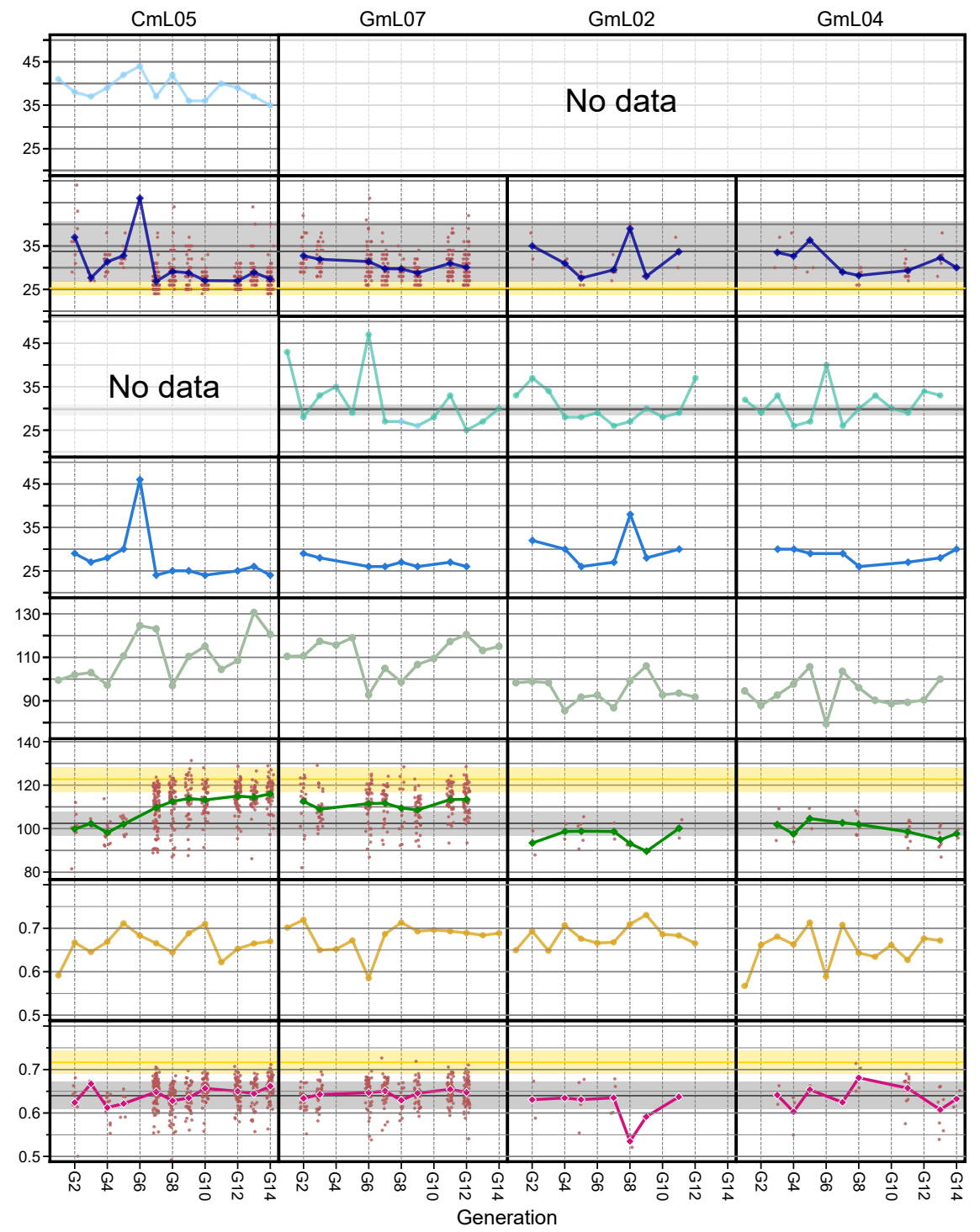


674 Fig. S6. Microbial traits of evolutionary $E$. coli lines CmL05 and GmL07 in comparison 675 with original $E$. coli strains BW25113, $\Delta$ intS and $\Delta$ mutS cultured in liquid medium. (a)

676 Growth curves ( 3 replicates each). Upper solid line is the trace of $\Delta$ intS growth curve, whereas

677 lower dotted line is the trace of CmL05 growth curve. (b) Morphology of bacterial cells. (c)

678 Quantification of cell size in terms of major axis length. (d) Motility of bacterial cells visualized

679 by rainbow plot for 2 sec. (e) Quantification of bacterial motility in terms of number of 680 swimming cells per 100 cells observed. (f) Characteristic cellular shape and growth mode in 681 microfluidic channels. From left to right, the micrographs show the microchannels harboring 682 E. coli cells with normal rod-like shape $(\Delta \mathrm{intS})$, filamentation shape ( $\Delta$ mutS), L-form-like 683 round shape (CmL05), extracellular void space and chained growth (CmL05), and extracellular 684 void space and solitary growth (GmL07). Arrows indicate the cells showing the extracellular 685 void space. (g) Frequency of the microchannels in which E. coli cells exhibited characteristic 686 cell shape and growth mode. The total numbers of microchannels observed in the time-lapse 687 measurements were 131 ( $\Delta$ intS), 137 ( $\Delta$ mutS), 149 (CmL05G13), and 143 (GmL07G12). (h) 688 Bacterial titers in adult females 35 days after emergence in terms of ntpII gene copies per insect. 689 In (c), (e) and (h), different alphabetical letters indicate statistically significant differences 690 (pairwise Wilcoxon rank sum test: $P<0.05$ ). 
bioRxiv preprint doi: https://doi org/10.1101/2022.0126.477692; this version posted January 28, 2022. The copyright holder for this

preprint (which was not certified by peer review) is the author/funder, who has granted bioRxiv a license to display the preprint in perpetuity. It is made available under aCC-BY-NC-ND 4.0 International license.

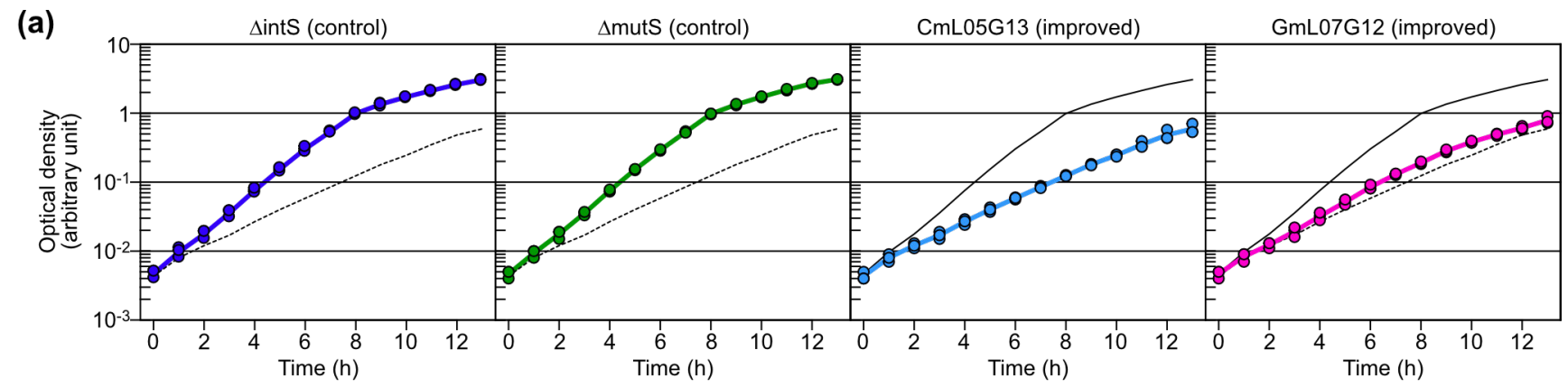

(b) BW25113 (wild-type)

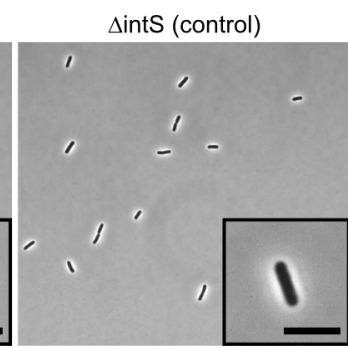

(c)

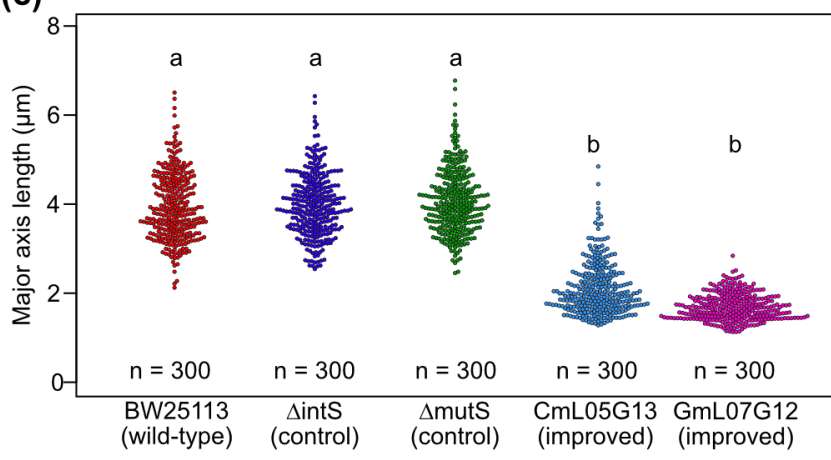

$\Delta$ mutS (control)

CmL05G13 (improved)

GmL07G12 (improved)

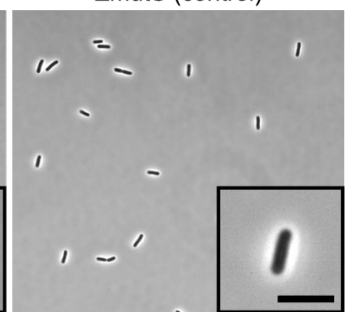

(e)

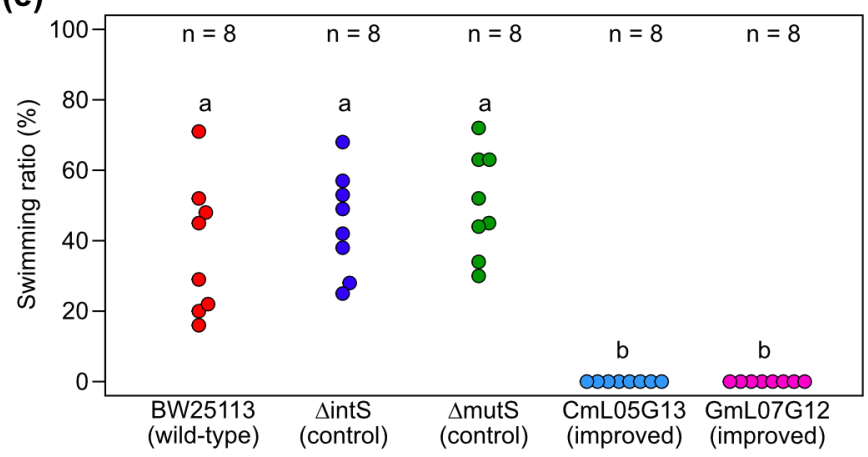

(d) BW25113 (wild-type)

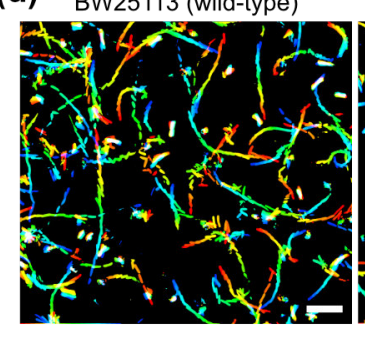

(f)

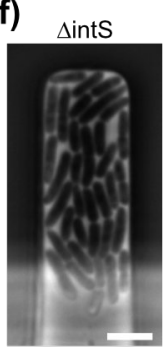

旁
$\Delta$ mutS
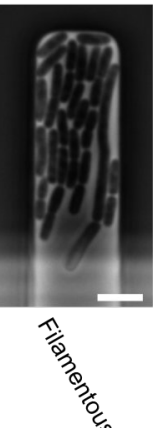

$\Delta$ intS (control)
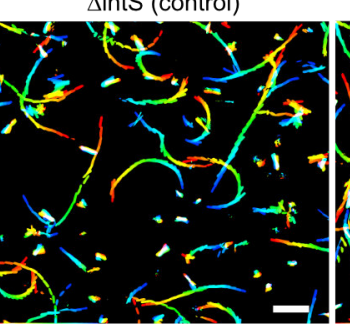

CmL05G13 (improved)

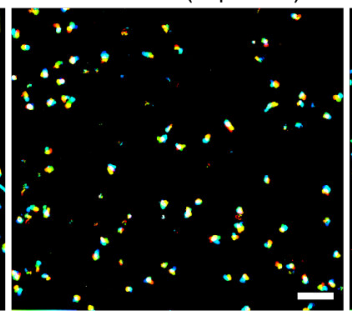

GmL07G12 (improved)

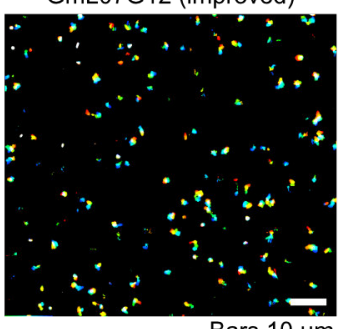

$\Delta$ mutS (control)

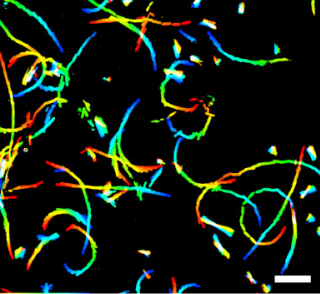

Bars $10 \mu \mathrm{m}$

CmL05G13

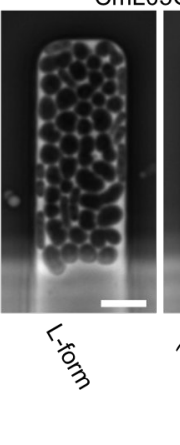

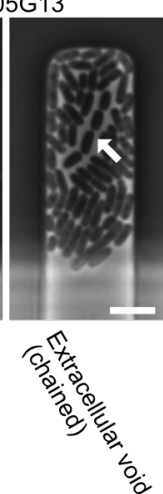
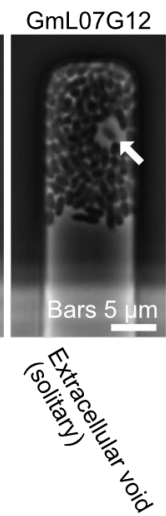

(g) $1007=$ L-form

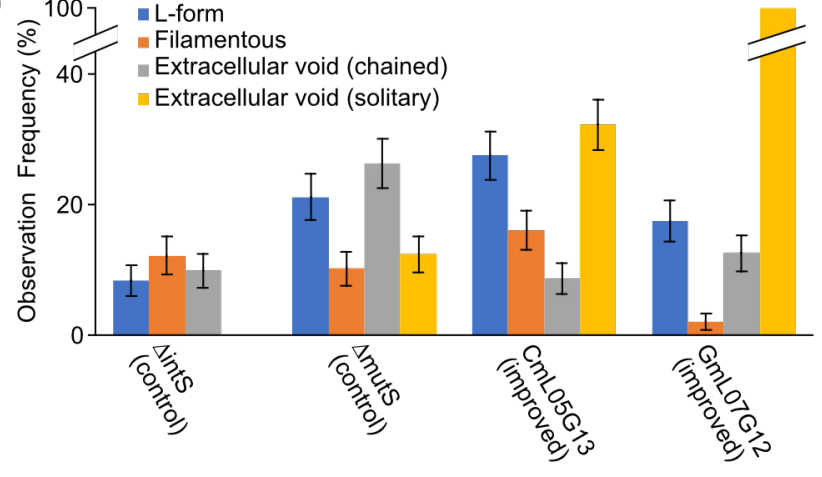

(h)

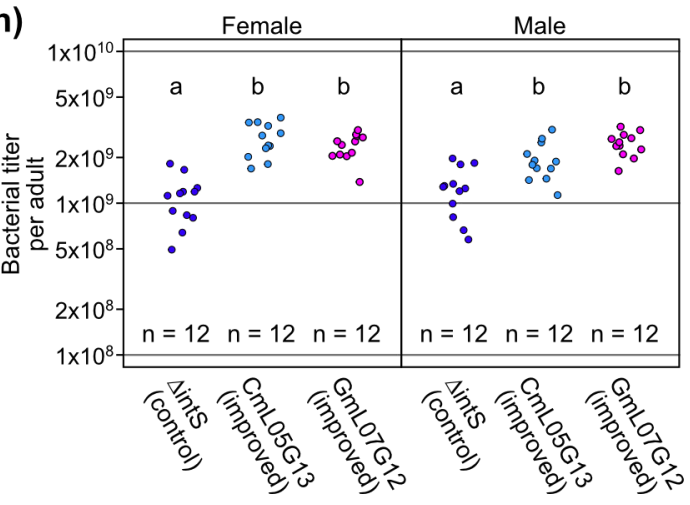


696 Fig. S7. Gene expression changes of evolutionary E. coli lines GmL07 and CmL05 before

697 and after improvement of host phenotypes. (a, b) Venn diagrams showing down-regulated

698 genes (a) and up-regulated genes (b) after the improvement of host phenotypes. (c) Expression

699 levels of genes involved in extracellular matrix (Curli fimbriae) production before and after the

700 improvement of host phenotypes. Asterisks indicate statistically significant differences (FDR

701 q-value $<0.01)$.

702

703

704 
a

Genes showing decreased expression after the improvement

In GmL07

In CmL05

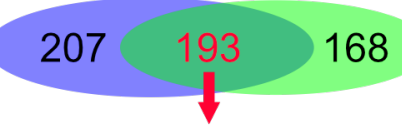

* Transporters (maltose, ribose, galactitol, trehalose, mannose, branched chain amino acids, etc.)

* Glyoxylate bypass

* Fatty acid degradation

* Curli fimbriae production

* Quorum sensing

* Acid tolerance b

Genes showing increased expression after the improvement

In GmL07

In CmL05

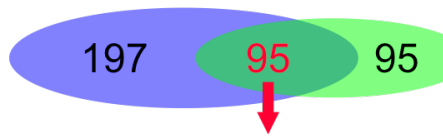

* Transporters (oligopeptide, Feenterobactin, $\mathrm{Fe}$ (III)

hydroxamate, etc.)

* DNA repair and recombination proteins (polV, etc.)

c Curli fimbriae production

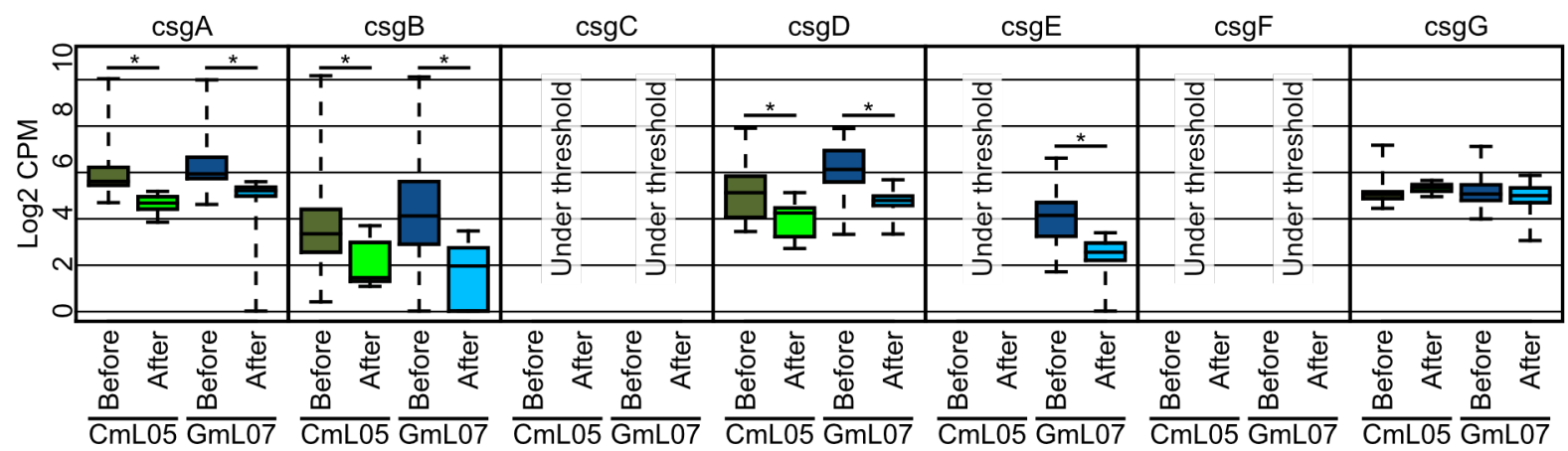


708 Fig. S8. Mutations in the genomes of evolutionary $E$. coli lines CmL05, GmL02, GmL04

709 and GmL07 in the experimental evolutionary course. Frequencies of 1,052 variants

710 identified in the experimental evolution lines and generations are color-coded. Vertical axis

711 represents the generations of the experimental evolution lines whereas horizontal axis

712 represents an array of 1,052 variants. This figure is the graphical representation of table S7.

713

714

715 
bioRxiv preprint doi: https://doi.org/10.1101/2022.01.26.477692; this version posted January 28, 2022. The copyright holder for this preprint (which was not certified by peer review) is the author/funder, who has granted bioRxiv a license to display the preprint in perpetuity. It is made available under aCC-BY-NC-ND 4.0 International license.

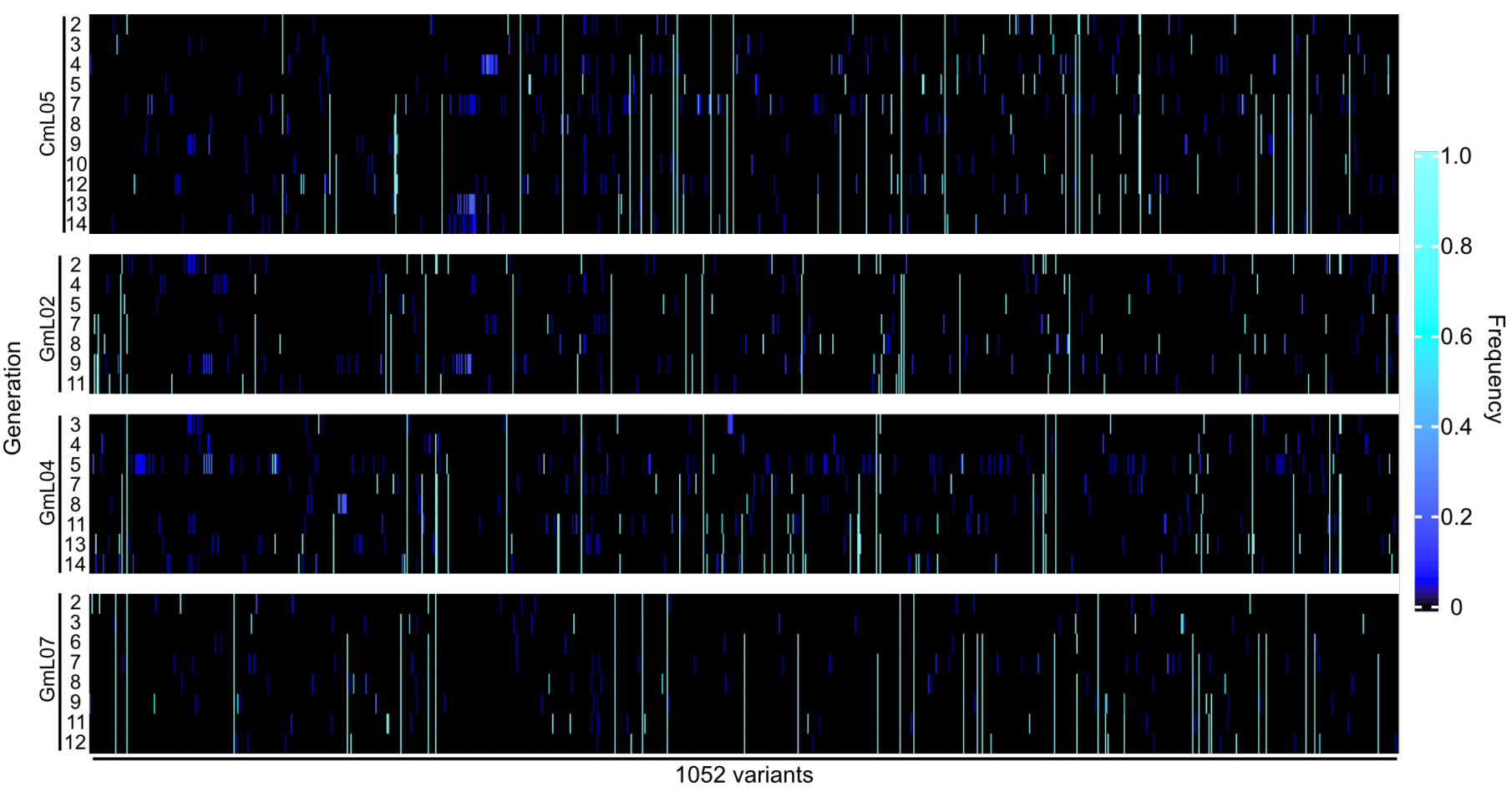


719 Fig. S9. Carbon catabolite repression (CCR) pathway and Crp-cAMP regulon of $E$. coli.

720 (a) CCR pathway repressed in the presence of glucose. (b) CCR pathway activated in the

721 absence of glucose. (c) Number of genes constituting the Crp-cAMP regulon of E. coli

722 estimated by RegulonDB (20).

723

724

725 
a CCR pathway repressed in the presence of glucose

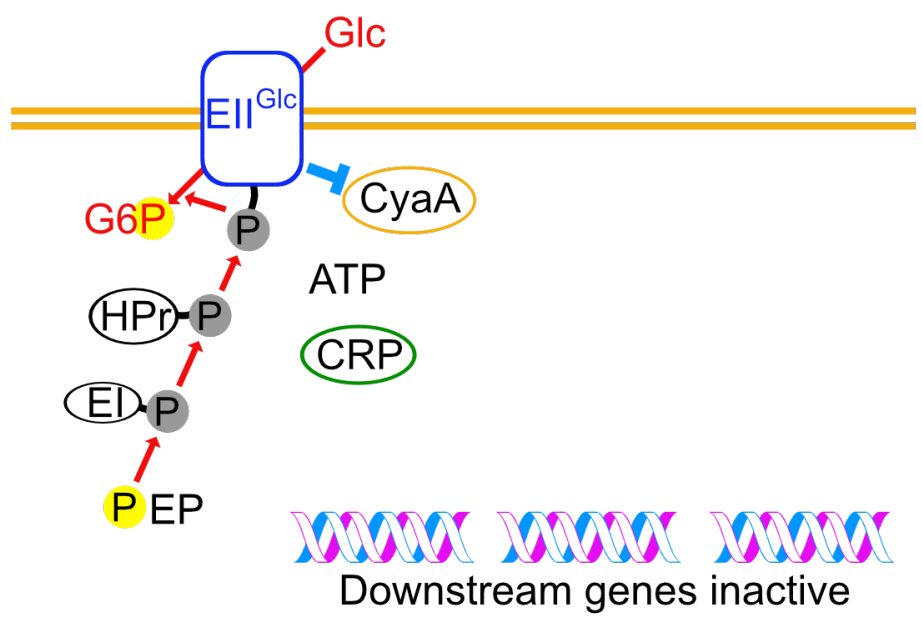

\section{b CCR pathway activated in the absence of glucose}

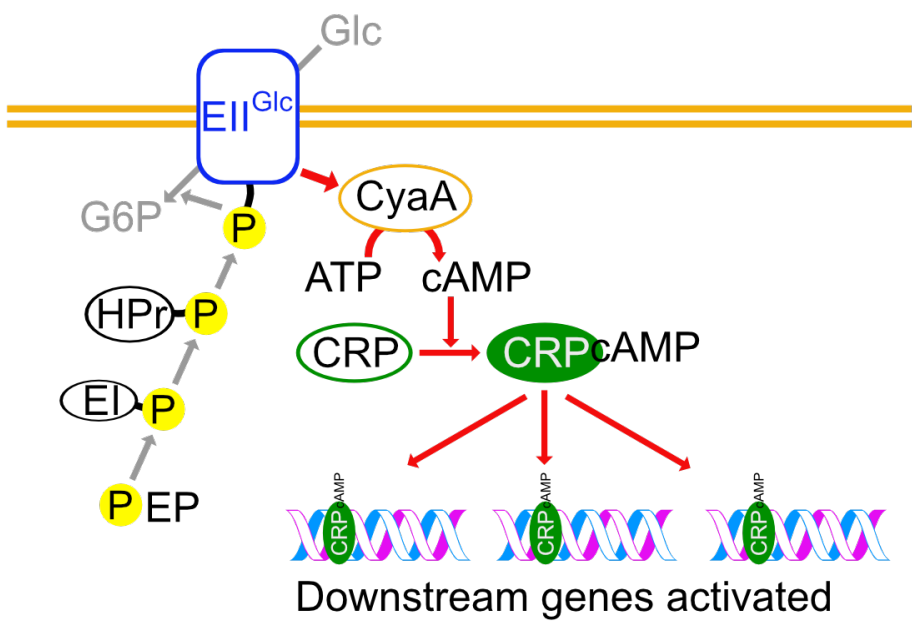

c Crp-cAMP regulon genes in $E$. coli

Regulated by Crp-cAMP 522 genes

Activated 390 genes 
729 Fig. S10. Genes commonly down-regulated in GmL07 and CmL05 after the

730 improvement of host phenotypes, and also down-regulated by disruption of Crp-cAMP

731 in $\boldsymbol{E}$. coli. (a) Venn diagram showing the commonly down-regulated genes. (b-i) Expression

732 levels of the commonly down-regulated genes in GmL07 and CmL05 after the improvement

733 of host phenotypes. (b) Transporter genes. (c) Carbohydrate metabolism genes. (d) Amino

734 acid metabolism genes. (e) Lipid metabolism genes. (f) Quorum sensing genes. (g)

735 Transcription factor genes. (h) Biofilm (= Curli fimbriae) formation genes. (i) Other genes. 


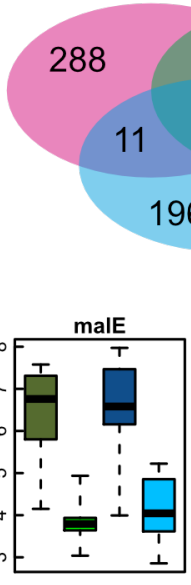

\section{b Transporters}
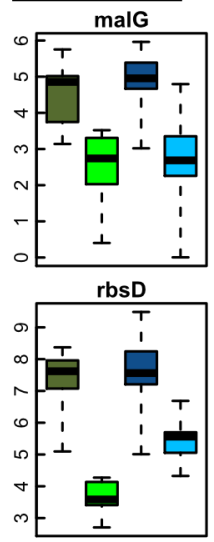

dcuA

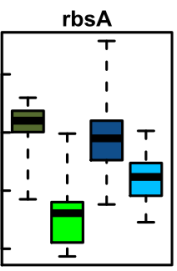

Decreased after improvement in GmL07

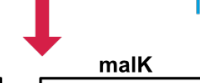

lamB
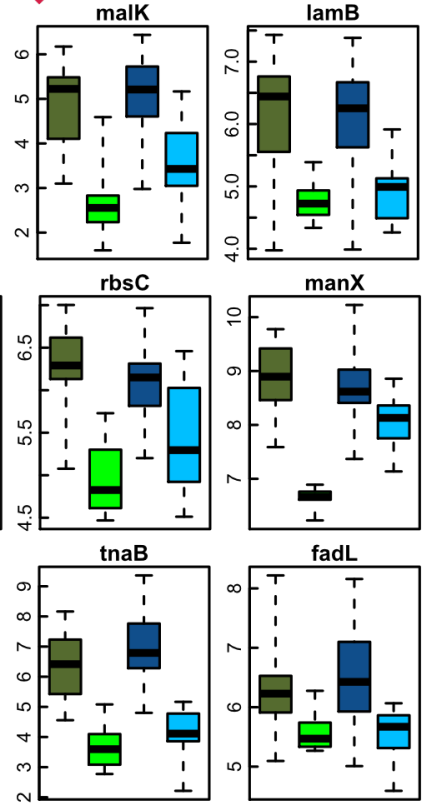

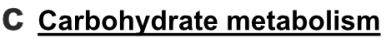
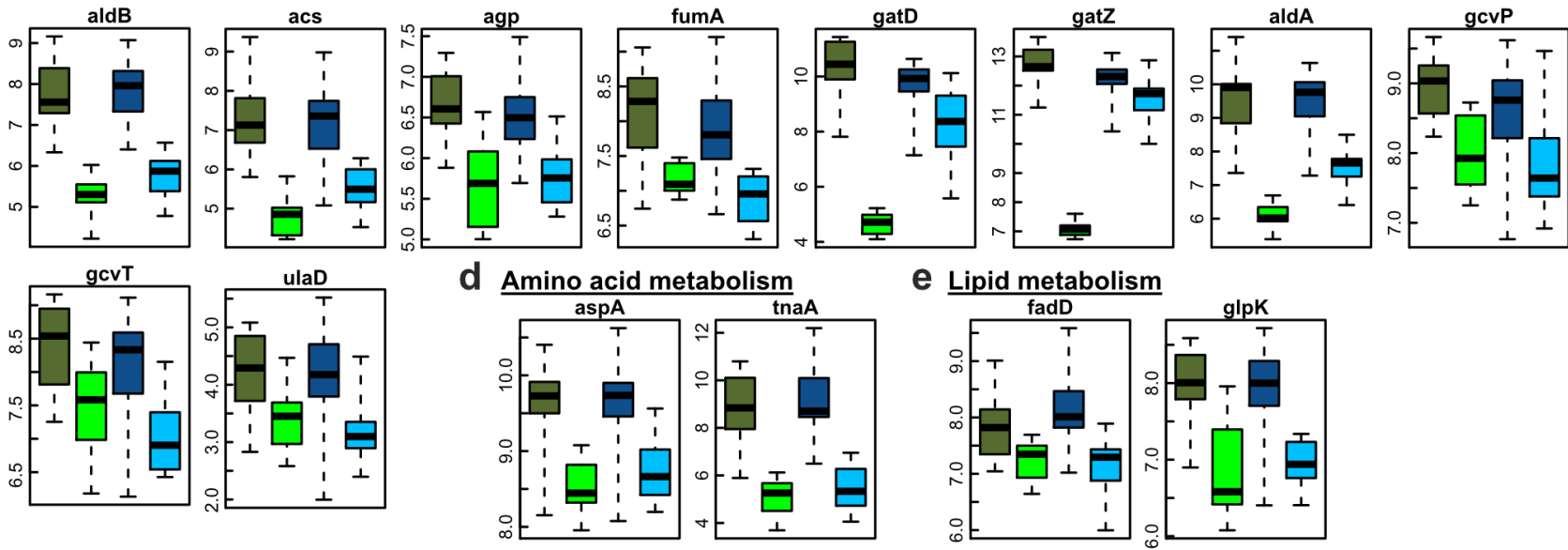

\section{e Lipid metabolism}

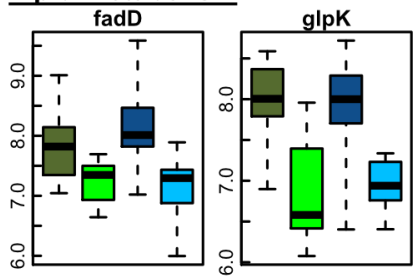

\section{f Quorum sensing}
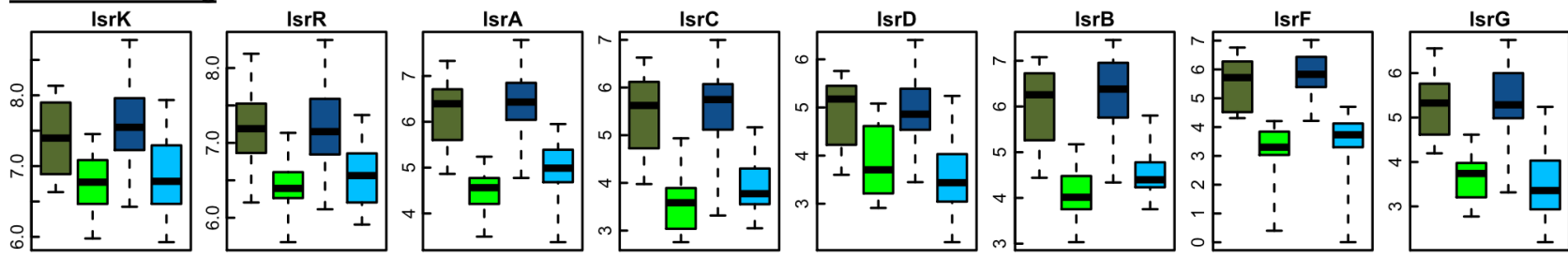

g Transcription factors
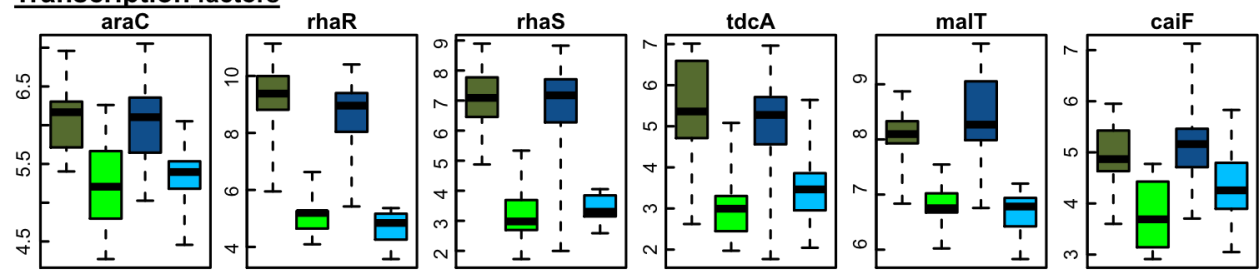

\section{$h$ Biofilm formation}
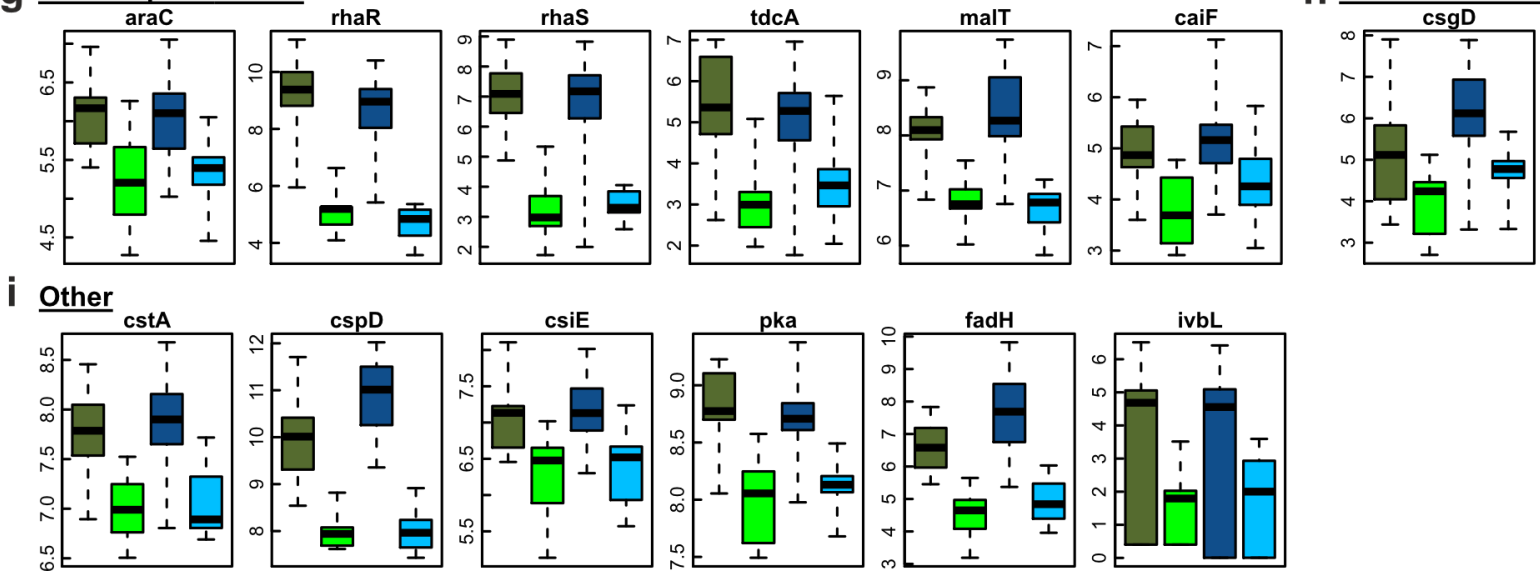
742 Fig. S11. Phenotypic traits of $\Delta$ cyaA and $\operatorname{crp}^{221 T>C}$ mutants of $\boldsymbol{E}$. coli. (a) Growth curves

743 (3 replicates each). Upper solid line is the trace of $\Delta$ intS growth curve, whereas lower dotted

744 line is the trace of CmL05 growth curve. (b) Morphology of bacterial cells. (c) Quantification

745 of cell size in terms of major axis length. (d) Motility of bacterial cells visualized by rainbow

746 plot for $2 \mathrm{sec}$. (e) Quantification of bacterial motility in terms of number of swimming cells

747 per 100 cells observed. (f) Bacterial titers in adult females 35 days after emergence in terms

748 of ntpII gene copies per insect. In (c), (e) and (f), different alphabetical letters indicate

749 statistically significant differences (pairwise Wilcoxon rank sum test: $P<0.05$ ). 
bioRxiv preprint doi: https://doi.org/10.1101/2022.01.26.477692; this version posted January 28, 2022. The copyright holder for this preprint (which was not certified by peer review) is the author/funder, who has granted bioRxiv a license to display the preprint in perpetuity. It is made available under aCC-BY-NC-ND 4.0 International license.

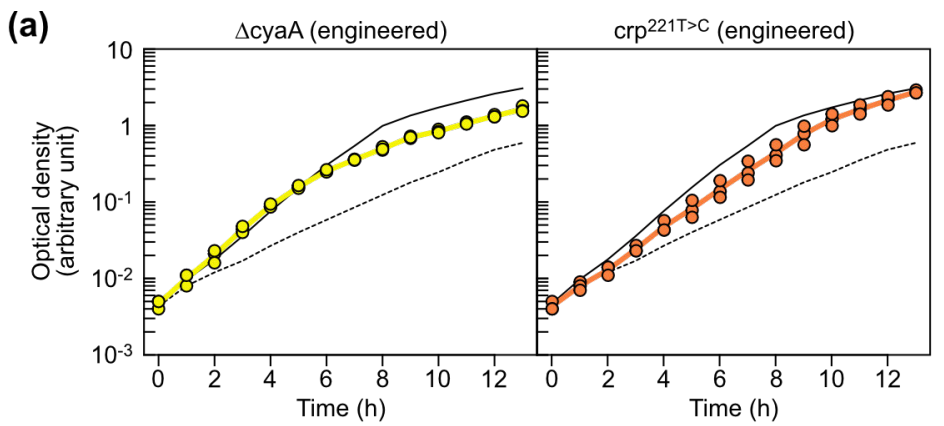

(b)

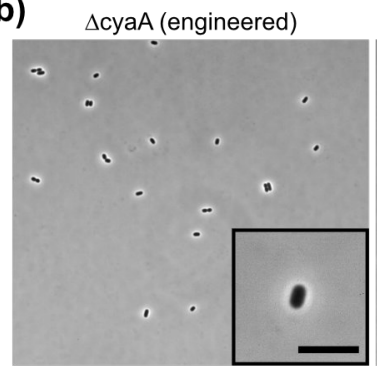
$\mathrm{crp}^{221 \mathrm{~T}>\mathrm{C}}$ (engineered)

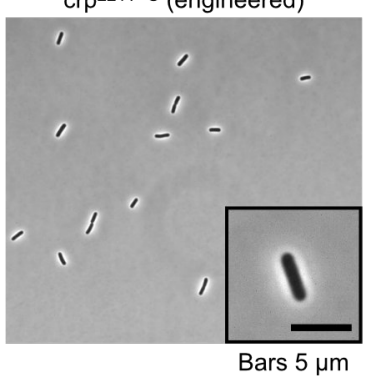

(c)

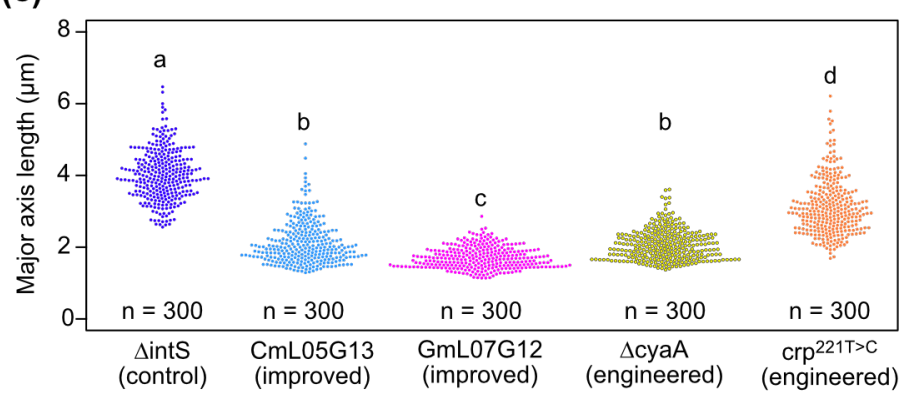

(d)

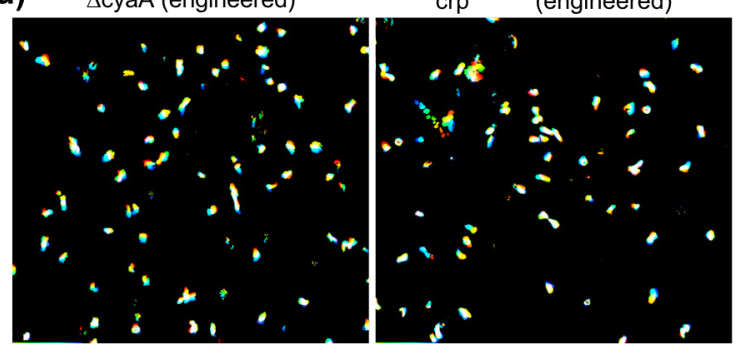

(e)

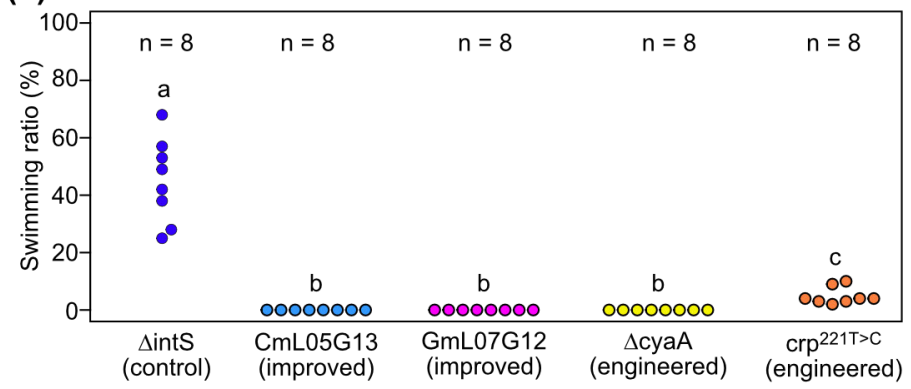

(f)

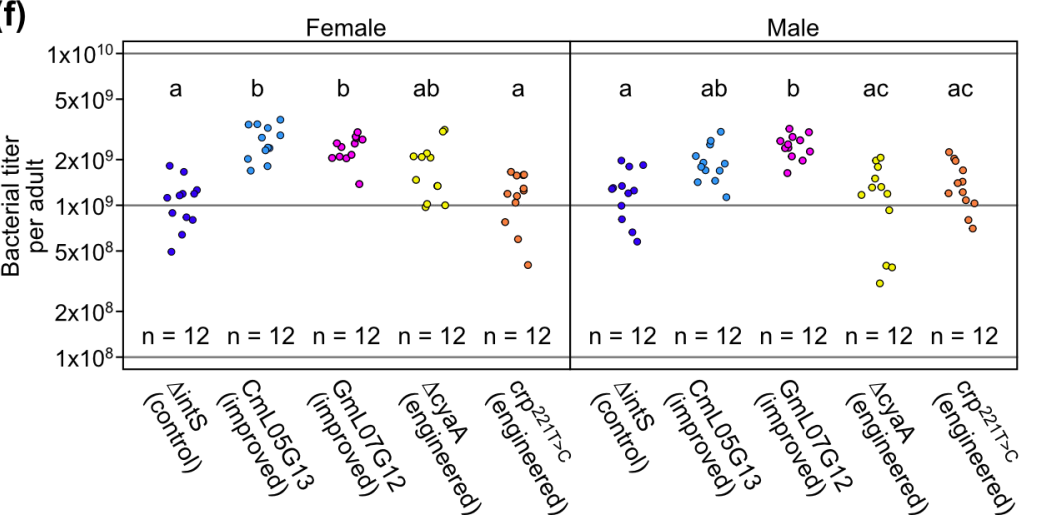

